\title{
Shareholder Engagement on Environmental, Social, and Governance Performance
}

\author{
Tamas Barko ${ }^{1}$ Martijn Cremers ${ }^{2} \cdot$ Luc Renneboog $^{3}$
}

Received: 6 July 2020 / Accepted: 25 May 2021 / Published online: 20 July 2021

(C) The Author(s) 2021

\begin{abstract}
We study behind-the-scenes investor activism promoting environmental, social, and governance (ESG) improvements by means of a proprietary dataset of a large international, socially responsible activist fund. We examine the activist's target selection, forms of engagement, impact on ESG performance, drivers of success, and effects on the targets' operations and value creation. Target firms are typically large and visible, perform well, and have high liquidity (stock turnover) and low ESG performance. Engagement induces ESG rating adjustments: firms with poor ex ante ESG ratings experience a ratings increase after complying with the activist's demands, whereas firms with high ex ante ESG ratings experience a ratings decrease following the revelation of their ESG problems. Activism that is focused on environmental and social issues is more likely to succeed if targets are ESG-sensitive (i.e., they have a strong ex ante ESG profile). Successful engagements boost targets' sales. Risk-adjusted excess stock returns (with four-factor adjustment and relative to a matched sample of nonengaged firms) of successful engagements outperform those of unsuccessful engagements by $2.7 \%$. Results are especially strong for firms with low ex ante ESG scores. Specifically, targeted firms in the lowest ex ante ESG quartile outperform matched peers by $7.5 \%$ in the year after the end of the engagement. Our results thus suggest that the activism regarding corporate social responsibility generally improves ESG practices and corporate sales and is profitable to the activist. Taken together, we provide direct evidence that ethical investing and strong financial performance, both from the activist's and the targeted firm's perspective, can go hand-in-hand together.
\end{abstract}

Keywords Activism · Corporate social responsibility $\cdot$ Socially responsible investing (SRI) Engagement $\cdot$ Environmental, Social and governance (ESG)

JEL Classification G15 · G23 · G32 · G34 · G39

Luc Renneboog

Luc.Renneboog@uvt.nl

Tamas Barko

tamas.barko@gmail.com

Martijn Cremers

mcremers@nd.edu

1 Prime Capital AG, Bockenheimer Landstraße 51-53, 60325 Frankfurt am Main, Germany

2 University of Notre Dame, 264 Mendoza College of Business, Notre Dame, IN 46556, USA

3 Tilburg University, PO Box 90153, 5000 LE Tilburg, The Netherlands

\section{Introduction}

Prominent activist investors such as hedge funds, pension funds, and influential individual shareholders and families often work to reshape corporate policies and strategy (e.g., (Becht et al., 2009; Becht et al., 2017). In this paper, we focus on activism from a different perspective. Given that socially responsible investments (SRI) have become increasingly important, we examine whether investor activism can promote corporate social responsibility (CSR), as reflected in firms' environmental, social, and governance (ESG) practices, and in turn affect corporate performance and investment results.

In a 1970 New York Times Magazine column, Milton Friedman famously stated that the "social responsibility of business is to increase its profits" (Friedman, 1970). In 
the past two decades, however, the notion of businesses' social responsibility has broadened, and socially responsible investing has grown from a niche segment to a mainstream phenomenon. Recent evidence suggests that (corporate) social responsibility is considered the primary proxy for ethical business practices, and for corporate reputation in particular (Leiva et al., 2016). Principles for Responsible Investing (2019) which establishes principles of responsible investing and guidelines for companies, reports that some 3000 institutions, managing about $\$ 90$ trillion, have endorsed their principles. In doing so, these institutions are declaring that corporate social responsibility is an essential part of their due diligence process and an integral factor in their investment decisions. Further, the Global Sustainable Investment Alliance (2019) (GSIA) estimates that over $\$ 30$ trillion of professionally managed assets are now explicitly allocated in accordance with ESG standards, driven not only by pension funds but also, increasingly, by mutual funds, hedge funds, venture capital funds, and real estate funds. ${ }^{1}$ And the trend is not limited to investment managers who explicitly label themselves as responsible. Increasingly, investors who consider themselves conventional are pushing for corporate social responsibility and ethics as well (Duuren et al., 2016).

A subset of ethical investors actively engages with the companies in their portfolios, requesting that they improve their environmental, social, and governance (ESG) practices (see, e.g., (Dimson et al., 2015; Doidge et al., 2019)). ${ }^{2}$ As Peattie and Samuel (2018) argue, ethically motivated

\footnotetext{
1 The GSIA definitions of sustainable investment, published in the Global Sustainable Investment Alliance (2013), have emerged as a global standard of classification. These are: 1 . Negative/Exclusionary Screening: the exclusion from a fund or portfolio of certain sectors, companies or practices based on specific ESG criteria; 2. Positive/ Best-in-class screening: investment in sectors, companies or projects selected for positive ESG performance relative to industry peers; 3 . Norms-Based Screening: screening of investments against minimum standards of business practice based on international norms, such as those issued by the OECD, ILO, UN and UNICEF; 4. ESG Integration: the systematic and explicit inclusion by investment managers of environmental, social and governance factors into financial analysis; 5. Sustainability Themed Investing: investment in themes or assets specifically related to sustainability (for example clean energy, green technology or sustainable agriculture); 6. Impact/Community Investing: targeted investments aimed at solving social or environmental problems, and including community investing, where capital is specifically directed to traditionally underserved individuals or communities, as well as financing that is provided to businesses with a clear social or environmental purpose; and 7. Corporate Engagement and Shareholder Action: the use of shareholder power to influence corporate behavior, including through direct corporate engagement (i.e., communicating with senior management and/or boards of companies), filing or co-filing shareholder proposals, and proxy voting that is guided by comprehensive ESG guidelines.

2 Throughout the paper, we use the terms "engagement" and "activism," as well as "engager" and "activist," interchangeably.
}

shareholder activism can be considered a challenge to established societal, ideological, and cultural phenomena that have hardly budged from the paradigm established by Friedman in the 1970s. Arguably, consumers and investors can both shape the landscape of social responsibility, but there is a growing consensus that a quasi-top-down approach, in which investors and asset managers aim to steer corporations towards more ethical business practices, is preferable (Salzmann, 2013).

In our paper, we study the effects of investor activism on corporate social responsibility (with a focus on environmental and social aspects) using a large, detailed, proprietary dataset on CSR activist engagements by a leading European investment management firm. The firm is managing SRI funds both for its own account and for its clients. To the best of our knowledge, this is the first paper to investigate such ESG engagements in an international context. In particular, this paper addresses the following questions: How does the activist investor choose target companies when aiming to improve ESG practices? How are such engagements carried out? Are such engagements successful in improving the targets' ESG performance? What drives success or failure in ESG activism? Is the activism visible in the targets' operations (e.g., accounting returns, profit margin, sales growth, etc.)? And what are the effects of the activism on investment value creation (i.e., stock returns)?

Our panel spans a decade (2005-2014), 660 engaged companies from around the globe, and 847 separate engagements. The engagements in our sample primarily concern social matters (43.3\%) and environmental issues (42.3\%); relatively few involve governance (14.4\%). As a result, these CSR engagements are quite different from activities by other activist investors (such as hedge funds) that focus on financial value and advocate for asset restructuring and governance improvement (e.g., (Becht et al., 2017)) but not on changes to social and environmental practices (as independent objectives).

We find that engaged companies typically have a higher market share and are followed by more analysts than their peers. Accordingly, in order to avoid selection bias and to account for unobserved heterogeneity, in subsequent analyses we match the engaged firms to control firms from the same industry that are similar ex ante in terms of size, market-to-book ratio, ESG rating, and ROA. In the case of environmental and social activism, the most common channel for engagement is either a letter or email addressed to the top management or the board of directors. In cases that relate to governance, the activist typically participates in shareholder meetings or meets in person with firm representatives (managers or non-executive directors).

In our sample, firms with lower ex ante ESG ratings are more likely to be engaged by the activist. Our evidence suggests that these engagements reveal information about the 
ESG practices at the engaged companies-information that is subsequently reflected in commercially available, independent ESG ratings. Targets with ex ante low ESG ratings see their ratings improve during the activism period. Targets with ex ante high ESG ratings experience a negative correction, suggesting that some of the activist investor's concerns had not been previously incorporated in the ratings and are publicly disclosed due to the activism.

The activist considers the engagement successful if the target sufficiently adjusts its policy on one or more previously determined ESG dimensions. Most of the engagement files in our sample $(60 \%)$ are considered successfully closed by the activist. Successful closings are more likely for targets with a larger market share, a good ESG track record, and earlier successful engagements. The presence of a large controlling shareholder, high short-term growth, and a larger cash reserve are associated with a lower likelihood of success. The activist's request for a material change from the engaged company (which we call a reorganization) reduces the likelihood of a successful outcome, relative to other engagement types (e.g., one that stimulates the target to be more transparent in its ESG policies).

Examining the changes in operating performance following engagement, we find no relation between engagement and accounting performance or any of its components. However, sales growth increases substantially, on average, following a successful engagement, which could indicate that the implemented changes appeal to a broader customer clientele. Finally, we find positive buy-and-hold stock returns in the month of the completion of the engagement and over subsequent time windows of 6 and 12 months. After the completion of an engagement, excess stock returns (with four-factor adjustment and relative to a matched sample) are higher after successful outcomes. The difference between successful and unsuccessful engagements is mainly significant within 6 to 12 months of the engagement's conclusion, and disappears subsequently. For example, the excess returns of targeted firms are higher than those of non-targeted peer firms by $2.7 \%$ over the 6 -month period following the engagement. Results are especially strong for firms with low ex ante ESG scores. Specifically, targeted firms in the lowest ex ante ESG quartile outperform their matched peers by $7.5 \%$ in the year after the end of the engagement. Our results thus suggest that the activism regarding corporate social responsibility generally improves ESG practices and corporate sales and is profitable to the activist.

Our findings do not support the argument that the activist fund and the firm engage in CSR efforts only for marketing or reputational purposes (Dupire \& M'Zali, 2018). The activist's dominant channel to engage the firm is direct contact that takes place behind the scenes and is kept private. Furthermore, the engagement seems to bring about tangible effects: (i) CSR ratings increase for ex ante low-rated firms and decrease for other engaged firms, (ii) there is an operational impact of the engagement, visible in sales growth, (iii) share prices increase more after successful engagements than after unsuccessful ones, and (iv) share prices increase more after successful reorganization cases that require changes in the firms' operations. All of these tangible effects are measured relative to peer companies that are not engaged and have similar ex ante CSR performance. After all, if the firm valued CSR as a marketing tool, why would it wait for the activist to engage it privately on CSR issues?

\section{Literature Review}

This paper links up with several related but confined strands of the literature: shareholder activism in general, SRI fund management and the impact of ESG screening devices, and the impact of unobservable activism (i.e., activism behind the scenes). Shareholder activism in general can be loosely partitioned into three categories (Dimson et al., 2015): traditional, hedge fund, and corporate social responsibility. Traditional activism is typically exercised by mutual funds or pension funds and generally concerns topics related to corporate governance or restructuring. Hedge fund activists seek to create financial value by influencing corporate strategy and structure. CSR activism aims to improve corporate citizenship and mainly focuses on issues related to environmental and social topics.

Social responsibility and ethical investments have religious roots that go back centuries (e.g., to the 17th century Quaker movement, as reported in Renneboog et al. (2008a)). Still, it was not until the 1960 s that socially responsible investing (SRI) gained momentum and began to capture the general public's interest. Growing concerns about human rights, pacifism, and environmental issues paved the way for today's SRI. The first modern investment vehicle catering to socially responsible investors was Pax World Fund, a mutual fund founded in 1971. Since then, SRI has expanded from a niche market strategy to a mainstream investment style. According to SRI reports, total SRI assets under management (AUM) have surpassed the $\$ 30$ trillion mark globally (Global Sustainable Investment Alliance, 2019), with \$12 trillion in the United States (US SIF, 2019) and \$4.45 trillion in Europe ((Eurosif, 2018)).

Fund managers apply various techniques and screens to form socially responsible portfolios. Bollen (2007) and Renneboog et al. $(2008 b, 2011)$ differentiate among distinct types of SRI screens. Negative screening, the most basic type, avoids investing in firms that sell products such as alcohol, tobacco, weaponry, abortion-related drugs, and pornography. Positive screening selects companies that meet above-average standards in areas such as the protection of the environment, the promotion of human rights, and the 
sustainability of investments. Negative and positive screens are often combined, yielding a third type: the so-called "transversal" (Capelle-Blancard \& Monjon, 2014), "sustainable," or "triple bottom line" ("people, planet, and profit") screens. Finally, the fourth generation of SRI funds combines the sustainable investing approach (third generation) with shareholder activism. In this approach, portfolio managers attempt to influence their portfolio companies' policies through direct engagement with the management/board of directors or through their use of voting rights at annual shareholder meetings.

The existing literature offers conflicting evidence on the financial returns of activism. English II et al. (2004) argue that the effect of activism is only cursory-apparent in the first six months following the announcement of activism and diminishing thereafter. Nelson (2006) concludes that abnormal returns are insignificant for any time window, once confounding effects are controlled for. Greenwood and Schor (2009) report that returns to activism are positive only in the cases where targeted companies are acquired as a result of activism. In a survey paper, Gillan and Starks (2007) find no positive effect of activism in the long run and no convincing evidence of a causal relation between activism and performance.

Other studies do show evidence of beneficial effects. One of the first studies of institutional investor activism, Smith (1996), found that activism by the California Public Employees' Retirement System (CalPERS) was able to generate shareholder wealth (the "CalPERS effect") but had no effect on operating performance. Using information from 13-D filings, Brav et al. (2008) document that firms targeted by activist hedge funds in the United States have abnormal returns of $7 \%$ around the announcement of activism, and that there is no reversal in returns in the subsequent year. Bebchuk et al. (2015) find no evidence of reversals in the 5-year period subsequent to the 13-D filings and observe lasting improvements in operating performance. ${ }^{3}$

Investor activism is not always conducted publicly: influential and major shareholders (institutional investors, families and individuals, and corporations) may be active behind the scenes. In a case study of the Hermes UK Focus Fund, Becht et al. (2009) find evidence that activism through private channels creates significant returns and increases operating performance in periods before the market becomes aware of it. Doidge et al. (2019) confirm, for a sample of

\footnotetext{
${ }^{3}$ However, Cremers et al. (2020) find that firms targeted by activist hedge funds have similar stock returns and lower increases in Tobin's Q compared to ex ante similar firms that were not targeted by activist hedge funds; this suggests that, while activist hedge funds may have stock-picking ability, their capacity to improve firm performance, on average, is unclear.
}

Canadian institutional investors, that engaging companies through private channels increases shareholder value.

Another body of literature on the performance of SRI funds (see, e.g., Margolis et al. (2011) and Barko and Renneboog (2016) for comprehensive overviews) indicates that SRI funds, at best, perform on par with their market benchmarks or their conventionally managed counterparts. Krueger (2013) shows that stock prices react to the release of CSR news, especially when the news is negative. However, a few papers show that some SRI funds are able to outperform: ** demonstrate that specialized management SRI firms that perform active portfolio selection are able to outperform conventional mutual funds, ${ }^{4}$ and Gibson et al. (2020) show that funds' investment strategies based on sustainability are related to the chosen investment horizon and yield positive risk-adjusted returns. Highlighting the pressure on individual firms to address ESG issues, the US SIF (2019) and Eurosif (2018) reports state that about 28\% and $40 \%$ of institutional investors filed ESG-related requests to their portfolio companies in the United States and Europe, respectively. Among these institutional investors, it is predominantly mutual funds and pension funds that contact companies regarding environmental and social issues (Dyck et al. 2019).

Using a proprietary sample of U.S. activist files, Dimson et al. (2015) also find that successful engagements in social and environmental topics induce positive returns and improvements in operating performance and corporate governance. Hoepner et al. (2020) find that ESG activism reduces left tail firm risk, especially when target firms respond with material actions to the activist's requests. Looking at shareholder proxy proposals, Flammer (2015) documents that proposals that pass only by a small margin generate significant returns and superior long-term accounting performance. It is not ex ante clear that specific activist tactics are effective across countries. One reason for this is that legal rules and corporate orientations toward shareholders or stakeholders (and the resulting regulation regarding ESG issues), as well as the voluntary adoption of CSR policies (e.g., reflecting social preferences or institutional development), differ across countries, inducing varying levels of CSR performance (among others, see Attig et al. (2016), Boubakri et al. (2016), and Liang and Renneboog (2017, 2020)).

It is interesting to dwell on the ethical perspectives of the type of ESG activism described in this paper. While a vast number of financial institutions, including banks and funds, are signatories of the United Nations Principles of

\footnotetext{
${ }^{4}$ This is in line with Cremers and Petajisto (2009), who show that mutual funds' outperformance of their benchmark is positively correlated with the portion of actively managed stocks in their portfolio.
} 
Responsible Investing, the incentives to have ESG as an important investment criterion are ultimately driven by investor demand. That investors care about not only about a financial return but also a (non-financial) "moral dividend" is clear both from investor surveys (e.g., (Lewis \& Mackenzie, 2000)) and money-flows in and out of investment funds. For instance, Renneboog et al. (2011) show that, while most funds' money-flows follow returns (high returns attract net inflows, poor returns the inverse), this is not the case for ESG (or SRI) funds, as negative returns in these funds do not cause investors to withdraw their money. The sensitivity to financial returns is less pronounced for these funds' investors, who seem to derive utility from the ethical impact of their investments. The fund activism captured in this paper is part of what is called "impact investing" (Scholtens, 2006), wherein investors try to generate a return and to ensure that their direct or indirect investments create societal value (Nilsson, 2008). Societal value can be created by reducing environmental externalities of production, improving labor conditions (throughout the whole supply chain), or ensuring inclusion of minorities in the corporate labor force, among other changes.

Using the terminology of Dembinski et al. (2003) on the ethical investment foundations, we observe that the ESG activist fund in this paper is at the intersection of their four ethical categories. The fund adheres to (i) value-based ethics, as it applies negative screening to specific "sin" industries and tries to induce changes to firms' ESG policies that are expected to generate share price increases; (ii) fructification-oriented ethics, as the fund demands that investees make policy changes that are meant to have a long-term effect (although we will see that the increased value generated by activism is quickly incorporated in share prices and traded away within 6-10 months after the successful closure of an engagement file); (iii) consequence-based ethics, as the fund aims to induce corporate behavioural change (this is visible, in this paper, in the fact that once a firm is convinced of the importance of ESG standards, the suggestions from subsequent ESG activism are more quickly adopted); and (iv) ethics envisaged as a discriminating criterion in the search for the best financial performance.

A key difference between the type of ESG activism in this paper and traditional corporate governance activism is that the former bypasses a conflictual approach in favor of a dialogue-based process (Logsdon \& Buren, 2009; Rehbein et al., 2013) in which corporations and shareholder activists aim for mutual agreement on the improvement of ESG issues.

As a guide to the structure of the remainder of the paper, we formulate the following research questions: What determines whether a firm is a suitable target for an ESG activist? What actions does shareholder engagement comprise? Does shareholder engagement successfully improve a target's ESG performance? What are the determinants of success or failure in ESG activism? Are the consequences of activism visible in a target's operations? And does shareholder engagement lead to value creation (i.e., improved stock returns)?

\section{Data}

\section{Engagement Data}

We have obtained a proprietary database on investor activism from a large European asset manager with more than $\$ 250$ billion in total net assets under management. The activist has offices and manages funds across Europe, North America, and Asia, and has long focused on ESG-specific investments. The activist mainly manages mutual funds and pension funds. It has a specialized team of analysts that combine in-house and independent third-party research to identify companies that have room for improvement in their ESG policies. Our database covers the universe of the asset manager's completed engagement cases over the period starting in the third quarter of 2005 and ending at the end of 2014. This enables us to test differences in engagement techniques and corresponding outcomes. As Liang and Renneboog (2017) and Sievänen et al. (2013) show, there are important differences in the perception and implementation of CSR across countries with different legal, political, and historical origins, such that the findings for one region do not necessarily apply to another. Therefore, we split the sample into three distinct regions based on the corporate domiciles: North America, Europe, and Other (mostly Asia-Pacific). Engaged companies are all either part of the MSCI All-Cap World Index or a major regional or country index. In total, our database has 847 completed engagement sequences involving 660 different companies.

The asset manager employs a specialized ESG-team that screens companies around the world. An activist case starts with the identification of a concern - an area where the target company can improve upon its ESG practices. To identify concerns, the engagement team relies on its own research as well as reports by specialized research companies and institutes (e.g., the environmental report of the World Bank or the UN Global Compact Monitor). An unforeseen event or crisis can also trigger an engagement case, if an engager screens a firm's ESG policies and concludes that they are insufficient to deal with the crisis. A prominent example of this is the 2010 Deepwater Horizon oil spill in the Gulf of Mexico, which BP arguably could have avoided or mitigated had it put in place clearly formulated environmental and disaster contingency plans (Watkins, 2010). The spill has since triggered numerous policy adjustments in the energy sector and enhanced scrutiny by the providers of CSR performance scores and activists. 
At the initiation of an engagement, the activist formulates a clearly defined objective. We first partition the engagement cases into two groups based on the engagement's objectives, distinguishing between those aimed at (i) changing the operations of the firm, e.g., implementing new environmental technology for better water management, or boardrestructuring ("reorganization"-oriented engagements); and (ii) providing more information on specific ESG dimensions, e.g., better reporting standards, such as the publication of a detailed sustainability report ("transparency"-oriented engagements). Each of these engagement categories can be further partitioned according to which of the E, S, and $G$ dimensions is the main dimension of interest.

At the start of the engagement, the activist also decides whether to carry out the engagement alone or as part of a coalition with one or more other activists, and whom to contact at the company. Typical contact persons in the engaged firm include executive and non-executive management (such as the CEO, investor relations personnel, and ESG representatives). The activist in this study has a selfimposed deadline of three years during which to achieve the desired outcome. If a successful outcome is reached, it usually occurs within 20 months. The ESG team advises its own in-house fund managers (of both SRI and conventional funds) and also works on commissioned cases on behalf of consulting clients' portfolios. The activist typically does not own a major block (one surpassing the 5\% reporting threshold), so it is generally not required to file 13-D reports in the United States.

In an environmentally related example, the engager contacted a large French cosmetics and beauty company regarding its use of palm oil, after a major UK retailer announced a ban on palm oil products from unsustainable sources. The engager was concerned that this ban, together with the public's skeptical attitude towards palm oil use, would affect the company's competitive position within its industry, and requested clarification regarding the use of palm oil in its products. The company provided the requested information, demonstrating that it was only a minor user of palm oil and that it was purchasing its supplies from sustainably managed sources. The activist asked the company to provide this information on its website. After the company complied and published a detailed sustainability report with a special focus on environmental reporting (demonstrating that its potential liability in relation to palm-olive concerns was very limited), this transparency case was successfully closed. This example shows two elements that are typical of the engagement cases in our sample: First, there is a trigger for the engagement - a significant event, a surfacing of new information, or a change or changes in the regulatory or competitive environment. Second, the engager formulates a specific request, and the engagement team follows through on this request, making sure the engaged company fulfills all of the requirements before the file is successfully closed. In "Appendix A", we provide more illustrations for each main ESG dimension.

For each engagement sequence, we verify that the "successful" closure of the engagement case is indeed determined by the ESG criteria that the activist initially set forth. Furthermore, we cross-reference outcomes with Factiva records and company websites to check the validity of the registered outcomes. We find no evidence that the data include erroneous reporting.

\section{Company-Level Data}

We obtain our firm-level data from a variety of sources: accounting and stock return data from Datastream, ESG performance indicators from Asset4 (available through Datastream), analyst coverage data from I/B/E/S, and ownership data from Morningstar and Orbis. We merge the data from different sources using ISINs, Datastream codes, and I/B/E/S identifiers, and cross-check, by means of company names, that all available data are properly matched. We use the global factor return data from Kenneth French's website to calculate abnormal returns. We define industries in various ways, following the classification on French's website for 10, 17, and 49 major industry groups, depending on the availability of a suitable control firm (see below). All variable definitions and their respective sources are provided in "Appendix C".

\section{Engagement Characteristics}

The engagement cases are categorized into three themes, based on whether the underlying goal is environmental, social, or governance-related. Within each theme, the engager distinguishes among a variety of topics and subtopics. ${ }^{5}$ We show the frequency with which these topics and subtopics occur in Panel A of Table 1. This panel also exhibits the percentage of successfully closed engagement files, the number of contacts between engager and target firm, the length of the engagement sequence, and the main contact type. The table shows that the engager focuses mostly on environmental and social topics, as these make up $42.3 \%$ and $43.3 \%$ of the 847 cases, respectively. About 60 percent of cases are closed successfully. ${ }^{6}$ The success rates vary by

\footnotetext{
5 A more detailed overview for the subthemes is presented in "Appendix B". In order to keep things tractable and to avoid working with very small subsamples, in the multivariate analysis we will focus on the three main ESG topics (for which we also distinguish between reorganization and transparency cases).

6 A success rate of $60 \%$ is higher than the rate reported in Dimson et al. (2015), but our sample covers a different time period. A high success rate in activist cases is not unprecedented as, for example,
} 
topic: firms are most responsive to engagements regarding public health issues, labor standards, climate change, reporting standards, and corporate governance issues. The average number of contacts with targeted firms is higher, and the average length of the engagement process is lower, in successful cases than in unsuccessful cases. The most frequently used means of contact is a formal letter or email. In cases involving public health issues, the engager and the firm often meet. In corporate governance engagements, the activist raises the issue at the annual or extraordinary shareholder meeting about half the time.

In Panel B, we further break down the engagements by ESG theme by determining whether (i) the aim of the engagement is to trigger reorganization (board or asset restructuring or operational changes) or to enhance transparency (see section "Engagement data"), and (ii) the engaged firm is initially open to the activist's demand (in which case receptiveness equals one) or resists the activist's demand (in which case receptiveness equals zero). An initial receptiveness, in management, to the activist's demands does not necessarily imply success at the end of the engagement period; this variable just measures the willingness of companies to start a conversation with the activist.

Overall, $51.5 \%$ of engagements aim at inducing a material change in company policy (reorganization). Two-thirds of the engaged companies are initially receptive to the engager's request and participate in an initial discussion (Panel B). When we study the percentage of successful cases over time (by year of engagement initiation), we observe that success rates by year vary between $61 \%$ and $78 \%$. The lone exception is 2009 , when the highest number of cases were initiated and the success rate dropped to $33 \%$, most likely due to the financial crisis. $^{7}$

We also examine the frequency of the various forms of communication between engager and target. Out of the nearly 3000 activities recorded in the case files, public channels such as annual or extraordinary general meetings and press releases account for only 170 (or 5.6\%), and these activities mainly occur in corporate governance cases. Onethird of the contacts occur via email, $18.5 \%$ by letter, and $11.4 \%$ via a conference call. In $10.9 \%$ of the cases, a personal meeting takes place (at the firm's premises in $2.8 \%$ of the cases, and at the engager's offices in $8.1 \%$ of the cases). ${ }^{8}$

\footnotetext{
Footnote 6 (continued)

Klein and Zur (2009) report a success rate of $60 \%$ and $65 \%$ for hedge fund and private equity activists, respectively. Furthermore, engagements that are triggered by previously unforeseen events or violations are likely to receive more support from corporate management, as discussed in Lee and Xiao (2020).

7 Table available upon request.

8 Table available upon request.
}

Over the whole sample period, the number of contacts between targets and engagers across all activist cases has been steady. Out of the 17 Fama-French industries, oil and petroleum firms and financial firms are engaged the most (93 and 86 cases, respectively), followed by pharmaceuticals, utilities, and retail companies. In terms of geographical focus, $54 \%$ of the targets are from Europe, $24 \%$ are from North America, $16 \%$ are from the Asia-Pacific region, and the remainder are from Latin America or Africa. ${ }^{9}$

\section{Engaging Target Firms}

\section{Matching Methodology}

To examine the determinants of the activist's decision, we first consider the characteristics of target companies in the year preceding the engagement relative to a matched sample. This allows us to mitigate the possibility that any observed ESG changes would have happened without the engagements. The matching procedure allows for an identification strategy that alleviates, to the highest degree possible, the endogeneity concerns that are inherent in all studies of investor activism. Our matching pool is the entire universe of companies in the Thomson Reuters Asset4 ESG database, which contains firms in major indices such as MSCI World, MSCI Europe, DJ Stoxx600, NASDAQ100, Russell 1000, FTSE250, and ASX 300 and which comprises more than 4200 stocks. The Asset4 ESG database has several advantages. First, it is an international index with broad coverage of large international companies, and contains virtually all our sample firms. Second, this database provides dynamic ESG performance scores, by a rating agency that is independent from the engager. This allows us to examine whether the engagements lead to ESG changes that are captured by outsiders. Third, Thomson Reuters is a for-profit organization, and the revenue stream for its ESG ratings comes from the SRI investors, who pay Thomson Reuters for access to them, rather than from the rated companies. This implies that rating shopping is unlikely to be an issue (as opposed to, for example, credit ratings that are paid for by the issuers; see Benmelech and Dlugosz (2009)).

To construct the matched sample, we take several steps. First, we exclude all engaged companies that are also part of the Asset4 database. Second, we restrict the pool to

\footnotetext{
${ }^{9}$ In Fig. 1, we show the distribution of engagement cases and their success rate over time. The figure shows a drop in the number of engagements around the Great Recession (2007-2009), with particularly low case counts in 2007 and 2008. The success rate of the cases initiated in this period also varies broadly, with the lowest rate-in terms of cases initiated in that year which were eventually completed being in 2009 .
} 


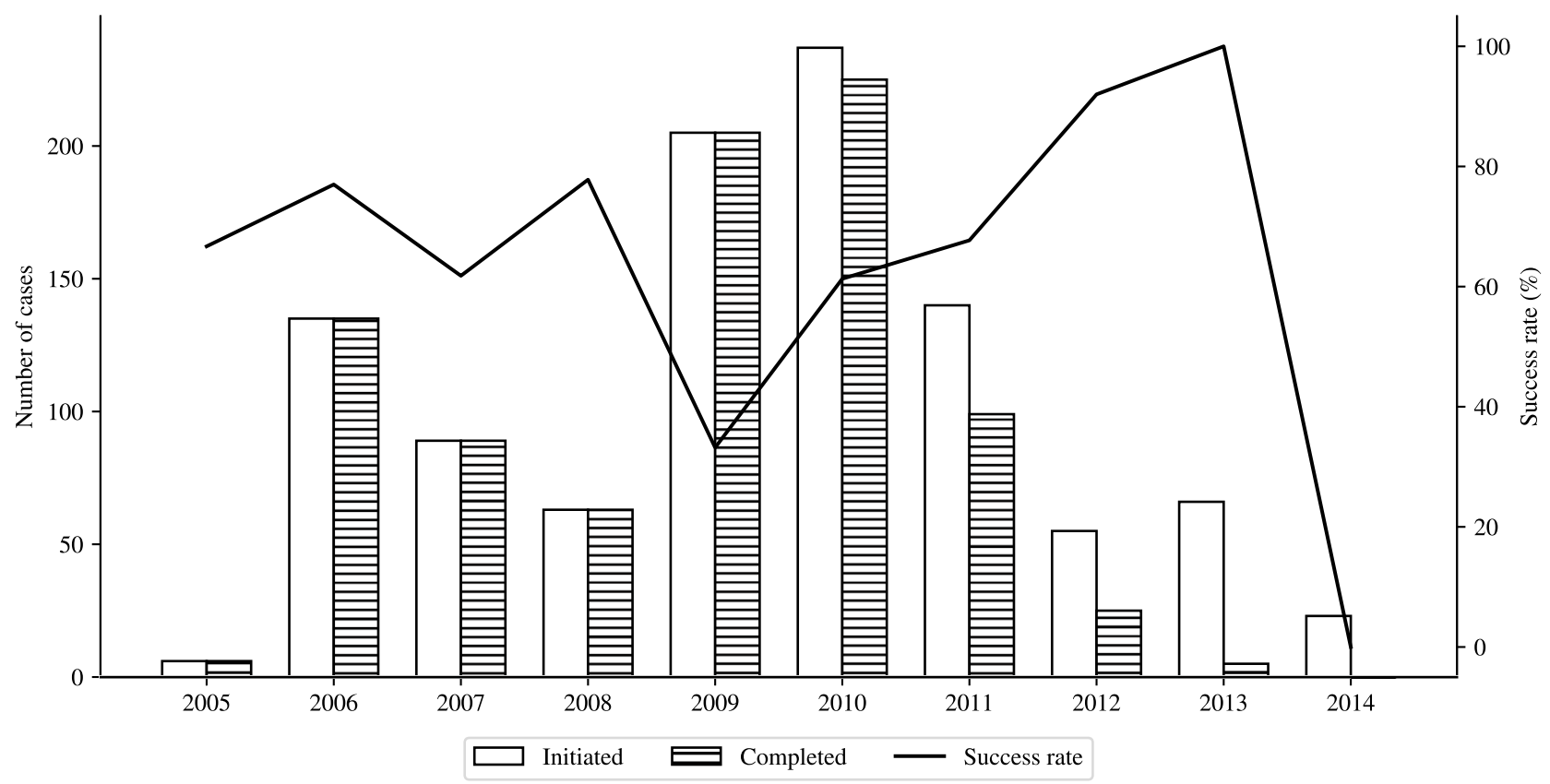

Fig. 1 Engagement case count and success rate by year. On the left axis, the figure shows the number of cases initiated in a given year, as well as the number of cases that were initiated in that year and were

industries based on the 49 Fama-French industry group classification. Third, we calculate the Mahalanobis distance metric for each possible engaged and matching company combination based on size, market-to-book ratio, ESG score, and ROA in the year prior to the engagement. The advantage of this matching method is that we do not impose a hierarchy on the matching variables by sequentially sorting companies into portfolios. Furthermore, the Mahalanobis distance is not sensitive to the scaling of the data and performs well with a small number of matching covariates (Stuart, 2010). The outcome of the matching procedure, the Mahalanobis distance, is an intuitive measure that takes the covariance of matching variables into account (and that reduces to the Euclidean distance if the covariances are equal to zero). We cannot find a match based on 49 industries for 14 engaged firms; for these companies, we relax the set of possible matches based on 17 (rather than 49) industries. After calculating the distance for each company in our universe, we pick the three companies with the lowest distance metric from the engaged company as the controls. For companies that have multiple engagement cases, we keep the same set of matching companies for subsequent engagements. As a robustness test, we re-estimate all our multivariate analyses with (i) a single best match and (ii) other matching methods based on propensity scores (Leuven \& Sianesi, 2003), but we do not report these results, as they lead to similar conclusions.

In the selection of our matching variables, we follow a well-established trend in the literature by matching on completed at some later date. On the right axis, the figure depicts the success rate of cases that were initiated that year and were subsequently closed successfully

industry, size, and market-to-book. Additionally, corporate social responsibility has been shown to significantly affect the cost of capital (see for example, El Ghoul et al. (2011)), so we include firms' ESG scores in our matching algorithm. Finally, to address the concern that a profitable firm may have higher ESG scores due to its financial slack (Hong et al., 2012), we also use ROA in calculating the Mahalanobis distance.

\section{Univariate Results}

We present summary statistics for target and matching firms in Table 2, testing the difference in means and medians between the engaged and matching sample using a paired t-test and a Wilcoxon signed-rank test, respectively. To test the difference between the means of the engaged and the control sample, we create a "pseudo-company" for each engaged company using the equally weighted mean of three matched companies, as in Brav et al. (2008). The pseudocompany characteristic is calculated as

$\tilde{X}_{i}=\frac{1}{3} \sum_{j=1}^{3} X_{j}$

where $\tilde{X}_{i}$ represents a characteristic variable for a pseudocompany for each engaged company $i$ and $X_{j}$ is the characteristic variable for each matched company. All variable 


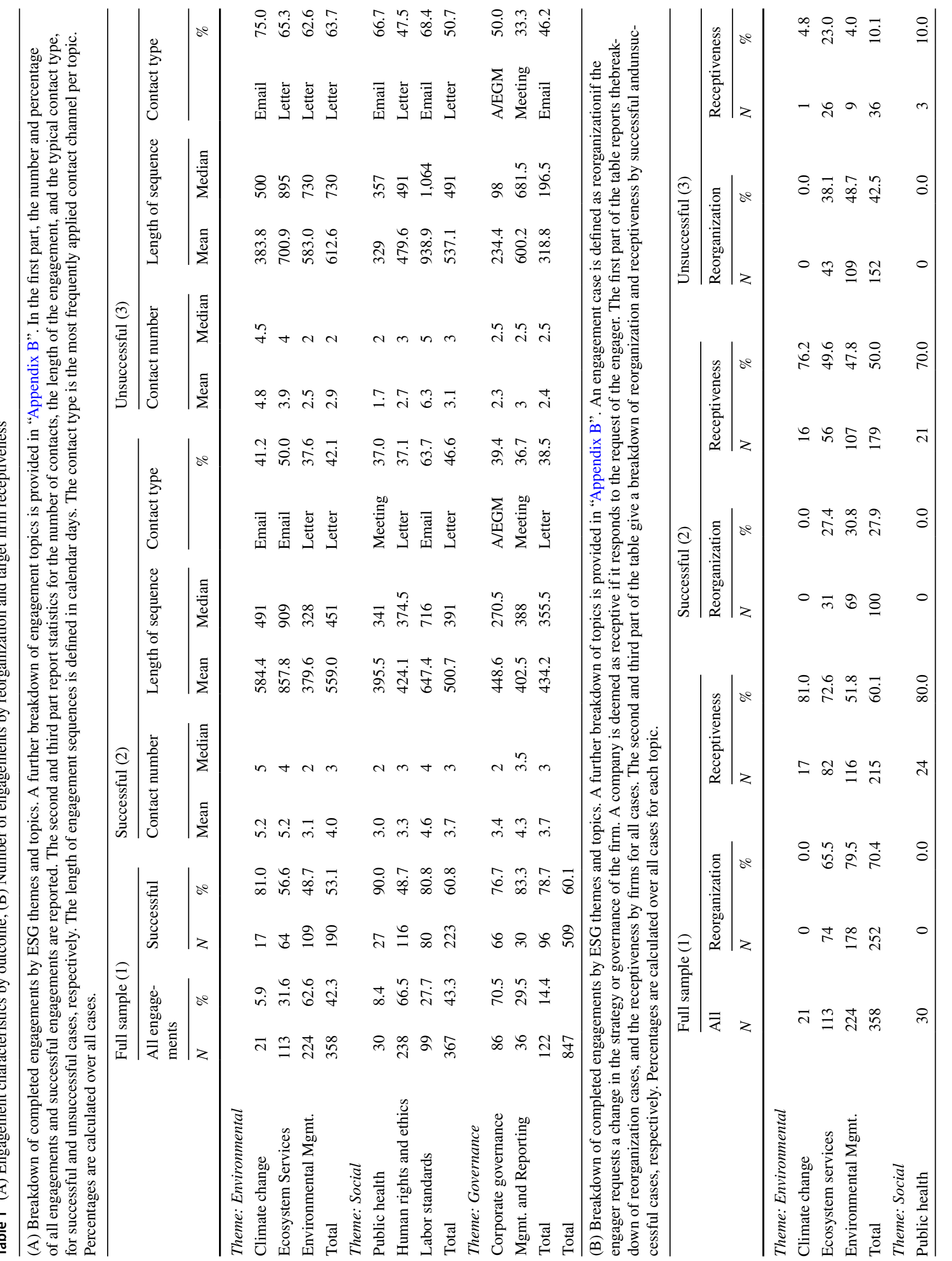




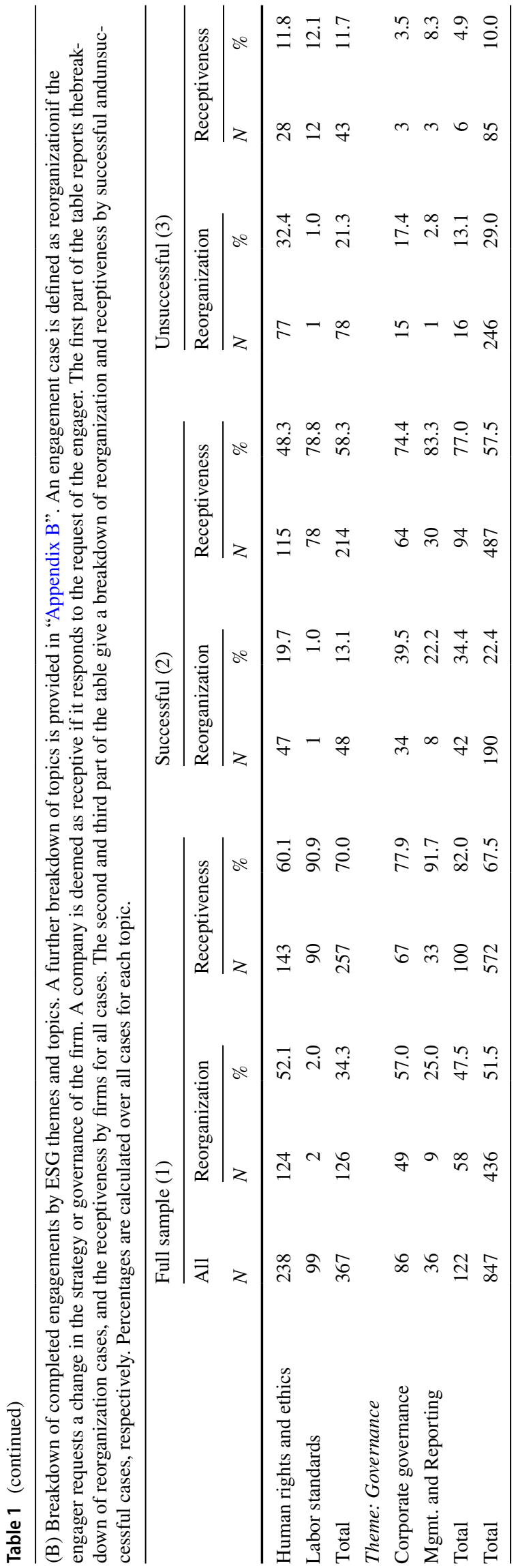

definitions and their respective sources are provided in "Appendix C".

\section{ESG Performance}

As explained above, we use ratings by Thomson Reuters Asset4 that capture the ESG attributes of target and matching companies. The "aggregate" ESG rating is the equally weighted average of the following four underlying sub-ratings or pillars: environmental, social, governance, and economic outlook issues. The first three pillars refer to the usual ESG topics, while the fourth, the economic pillar, addresses the firm's financial performance and economic outlook. We document, in Table 2, that engaged companies, both at the aggregate ESG level and the individual pillar level, have significantly higher ESG scores than nonengaged firms. This observation is similar to Dimson et al. (2015), who also find that engaged companies already have a higher standard of corporate governance in place prior to investor activism. We also use a modified version of the Entrenchment index (E-index) of Bebchuk et al. (2009). Our model includes four of their six proposed governance provisions-poison pills, golden parachutes, staggered boards, and supermajority for bylaws and mergers - because Asset4 records these variables for all companies. We find that, on average, engaged firms do not have a different aggregate level of these governance provisions than non-engaged firms. Following Boubakri et al. (2016), we also construct a country ESG sentiment measure by calculating the mean ESG rating of all firms within that country in a given year. Table 2 shows that targeted firms are, on average, located in higher ESG sentiment countries.

\section{Risk and Performance}

The annual stock returns of engaged companies are not statistically different from those of the matched, non-engaged firms, but the engaged firms exhibit lower stock return volatility and greater liquidity. Engaged firms also have somewhat higher accounting returns, sales growth, Tobin's Q, and interest coverage. Economically, however, these differences are modest. Engaged companies have somewhat higher market share in their respective industries. Other variables (profit margin, sales growth, asset turnover) do not differ between the groups.

\section{Cash and Expenses}

Free cash flow and cash holding figures are comparable across the two samples (Table 2). Engaged companies have slightly lower capital expenditures as a fraction of total assets $(0.4 \%)$, spend more on advertising, and pay out more in dividends, both in absolute terms and as a percentage of their net income. Cash holdings, free cash flows, and 
Table 2 Descriptive statistics

This table reports summary statistics for all variables. For each case, we keep the first firm-year observation and use a lag of 1 year. The control sample is determined by Mahalonobis distance metric matching. For all engaged companies, we draw three matching pairs with replacement. The Mahalanobis distance is determined based on industry, ESG score, size, market-to-book ratio and ROA. The $t$-statistics stand for the difference in means between the engaged and the control group. The $Z$-score is calculated for the Wilcoxon signed rank test, for which we use the median difference between the engaged firm and the control group. For the $t$-statistics and $Z$-scores we report $p$-values in brackets. Variables are winsorized at $2.5 \%$ on both tails of the distribution. All variable definitions are in the Appendix.

\begin{tabular}{|c|c|c|c|c|c|c|c|c|c|c|}
\hline \multirow[t]{2}{*}{ Variable } & \multicolumn{6}{|c|}{ Full sample } & \multicolumn{2}{|c|}{ Control } & \multicolumn{2}{|c|}{ Difference } \\
\hline & Obs. & Mean & Sdev. & $25 \%$ & Median & $75 \%$ & Obs. & Mean & t-test & Rank \\
\hline \multicolumn{11}{|l|}{ ESG ratings } \\
\hline ESG sentiment & 819 & 57.769 & 12.893 & 50.889 & 57.044 & 67.460 & 2,534 & 50.465 & {$[0.000]$} & {$[0.000]$} \\
\hline ESG score & 705 & 77.315 & 23.821 & 70 & 88.520 & 94.010 & 2,337 & 67.861 & {$[0.000]$} & {$[0.000]$} \\
\hline Environmental score & 705 & 74.627 & 25.317 & 63.900 & 86.990 & 93.030 & 2,336 & 67.412 & {$[0.000]$} & {$[0.000]$} \\
\hline Social score & 705 & 76.913 & 23.534 & 67.860 & 86.770 & 94.010 & 2,336 & 67.194 & {$[0.000]$} & {$[0.000]$} \\
\hline Governance score & 705 & 64.412 & 26.324 & 45.940 & 73.910 & 85.530 & 2,336 & 57.244 & {$[0.000]$} & {$[0.000]$} \\
\hline Economic score & 705 & 71.345 & 26.151 & 54.780 & 81.480 & 92.660 & 2,336 & 63.508 & {$[0.000]$} & {$[0.000]$} \\
\hline E-index & 641 & 0.376 & 0.252 & 0.250 & 0.250 & 0.500 & 1,988 & 0.360 & {$[0.136]$} & [0.151] \\
\hline \multicolumn{11}{|l|}{ Risk and performance } \\
\hline Buy-and-hold return & 833 & 0.075 & 0.459 & -0.209 & 0.067 & 0.290 & 2,544 & 0.052 & {$[0.224]$} & [0.835] \\
\hline Volatility & 826 & 0.324 & 0.183 & 0.185 & 0.280 & 0.409 & 2,530 & 0.327 & [0.609] & [0.001] \\
\hline Amihud ILLIQ & 827 & 0.176 & 0.851 & 0 & 0 & 0.002 & 2,452 & 0.164 & {$[0.703]$} & {$[0.000]$} \\
\hline Asset turnover & 846 & 0.848 & 0.566 & 0.460 & 0.760 & 1.130 & 2,544 & 0.827 & {$[0.375]$} & [0.371] \\
\hline Profit margin & 841 & 0.080 & 0.147 & 0.035 & 0.071 & 0.123 & 2,537 & 0.083 & {$[0.637]$} & {$[0.177]$} \\
\hline ROA & 846 & 0.059 & 0.064 & 0.020 & 0.052 & 0.090 & 2,544 & 0.053 & [0.009] & {$[0.000]$} \\
\hline ROE & 846 & 0.157 & 0.166 & 0.086 & 0.152 & 0.235 & 2,544 & 0.133 & {$[0.000]$} & {$[0.000]$} \\
\hline Sales growth & 835 & 0.101 & 0.290 & -0.061 & 0.079 & 0.219 & 2,534 & 0.109 & {$[0.445]$} & {$[0.020]$} \\
\hline Market share & 847 & 0.028 & 0.030 & 0.004 & 0.015 & 0.048 & 2,544 & 0.017 & {$[0.000]$} & {$[0.000]$} \\
\hline Market-to-book & 843 & 2.578 & 1.986 & 1.338 & 1.982 & 3.202 & 2,544 & 2.361 & {$[0.001]$} & {$[0.255]$} \\
\hline Tobin's Q & 843 & 1.977 & 1.284 & 1.124 & 1.604 & 2.392 & 2,544 & 1.891 & {$[0.073]$} & {$[0.033]$} \\
\hline \multicolumn{11}{|l|}{ Cash and expenses } \\
\hline Cash holding & 846 & 0.066 & 0.073 & 0.019 & 0.041 & 0.084 & 2,544 & 0.067 & {$[0.771]$} & {$[0.000]$} \\
\hline CapEX & 846 & 0.053 & 0.046 & 0.021 & 0.041 & 0.075 & 2,544 & 0.057 & {$[0.060]$} & {$[0.000]$} \\
\hline Operating expenses & 817 & 0.862 & 0.128 & 0.806 & 0.881 & 0.938 & 2,532 & 0.862 & {$[0.933]$} & {$[0.779]$} \\
\hline SGA & 664 & 0.178 & 0.152 & 0.053 & 0.141 & 0.271 & 2,085 & 0.168 & [0.114] & {$[0.754]$} \\
\hline \multicolumn{11}{|c|}{ Size and capital structure } \\
\hline Log total assets & 846 & 9.623 & 1.858 & 8.461 & 9.862 & 11.060 & 2,544 & 9.293 & {$[0.000]$} & {$[0.000]$} \\
\hline Log sales & 841 & 9.146 & 1.719 & 8.177 & 9.549 & 10.617 & 2,537 & 8.798 & {$[0.000]$} & {$[0.000]$} \\
\hline Log market equity & 843 & 9.164 & 1.752 & 8.095 & 9.486 & 10.802 & 2,544 & 8.907 & {$[0.000]$} & {$[0.000]$} \\
\hline Book leverage & 846 & 0.327 & 0.220 & 0.161 & 0.302 & 0.461 & 2,544 & 0.320 & {$[0.381]$} & [0.408] \\
\hline Tangibility ratio & 845 & 0.313 & 0.234 & 0.119 & 0.271 & 0.479 & 2,538 & 0.338 & {$[0.010]$} & {$[0.000]$} \\
\hline Equity issuance & 847 & -0.002 & 0.005 & 0.000 & 0.000 & 0.000 & 2,544 & -0.002 & {$[0.077]$} & {$[0.000]$} \\
\hline Debt issuance & 847 & 0.031 & 0.110 & -0.021 & 0.008 & 0.063 & 2,544 & 0.030 & {$[0.770]$} & {$[1.000]$} \\
\hline \multicolumn{11}{|l|}{ Other } \\
\hline Dividend yield & 843 & 0.029 & 0.027 & 0.011 & 0.024 & 0.040 & 2,544 & 0.026 & {$[0.012]$} & {$[0.138]$} \\
\hline Dividend payout & 846 & 0.389 & 0.508 & 0.121 & 0.325 & 0.525 & 2,544 & 0.353 & {$[0.070]$} & {$[0.756]$} \\
\hline Company age & 845 & 51.850 & 52.544 & 14 & 37 & 81 & 2,544 & 52.573 & {$[0.681]$} & {$[0.000]$} \\
\hline Analysts & 810 & 19.076 & 10.621 & 11 & 19 & 27 & 2,502 & 14.169 & {$[0.000]$} & {$[0.000]$} \\
\hline \multicolumn{11}{|l|}{ Ownership } \\
\hline Holding of engager & 847 & 0.002 & 0.002 & 0 & 0.001 & 0.002 & 2,544 & 0.001 & {$[0.051]$} & {$[0.580]$} \\
\hline Average ownership & 847 & 0.048 & 0.077 & 0.011 & 0.019 & 0.048 & 2,544 & 0.046 & [0.314] & {$[0.000]$} \\
\hline Blockholders & 847 & 3.851 & 1.813 & 3 & 4 & 5 & 2,544 & 4.092 & {$[0.001]$} & {$[0.000]$} \\
\hline Funds & 847 & 0.018 & 0.068 & 0 & 0 & 0 & 2,544 & 0.015 & [0.196] & {$[0.000]$} \\
\hline
\end{tabular}


Table 2 (continued)

This table reports summary statistics for all variables. For each case, we keep the first firm-year observation and use a lag of 1 year. The control sample is determined by Mahalonobis distance metric matching. For all engaged companies, we draw three matching pairs with replacement. The Mahalanobis distance is determined based on industry, ESG score, size, market-to-book ratio and ROA. The $t$-statistics stand for the difference in means between the engaged and the control group. The $Z$-score is calculated for the Wilcoxon signed rank test, for which we use the median difference between the engaged firm and the control group. For the $t$-statistics and Z-scores we report $p$-values in brackets. Variables are winsorized at $2.5 \%$ on both tails of the distribution. All variable definitions are in the Appendix.

\begin{tabular}{|c|c|c|c|c|c|c|c|c|c|c|}
\hline \multirow[t]{2}{*}{ Variable } & \multicolumn{6}{|c|}{ Full sample } & \multicolumn{2}{|c|}{ Control } & \multicolumn{2}{|c|}{ Difference } \\
\hline & Obs. & Mean & Sdev. & $25 \%$ & Median & $75 \%$ & Obs. & Mean & t-test & Rank \\
\hline Hedge fund \& PE & 847 & 0.009 & 0.020 & 0 & 0.003 & 0.007 & 2,544 & 0.010 & [0.172] & {$[0.000]$} \\
\hline Individuals & 847 & 0.018 & 0.068 & 0 & 0 & 0 & 2,544 & 0.015 & [0.196] & {$[0.000]$} \\
\hline Independent firm & 829 & 0.840 & 0.367 & 1 & 1 & 1 & 2,498 & 0.848 & [0.547] & [0.000] \\
\hline
\end{tabular}

operating expenses do not differ from those of matched firms.

\section{Size and Capital Structure}

Engaged companies are significantly larger in terms of assets, sales, and market value of equity, but have significantly fewer tangible assets. Their book leverage is similar to that of their matched peers.

\section{Ownership}

Table 2 also reveals that the average holding of our activist engager in engaged firms is small but still significantly higher than its average holding in the matched counterparts. Engaged companies have fewer blockholders (owning a stake of $5 \%$ or larger), but when we consider the different types of owners (e.g., financial institutions, industrial companies, the government, hedge funds and private equity, individuals and families), we find no meaningful differences. The seemingly high number of blockholders (Edmans and Holderness, 2017) is driven by firms outside of North America. When we partition the sample into North American, European, and other domiciled firms, we see that North American firms, on average, have three blockholders, European firms have four, and other, mainly Asian companies have more than four. The majority of engaged firms are independent companies, with no shareholder controlling $25 \%$ or more of the shares through direct or indirect holdings.

\section{Multivariate Results}

In Table 3, we show the results of probit regressions estimating the likelihood of being engaged by the activist. We first analyze whether firm size, performance, market share, leverage, stock liquidity, cash holdings, dividend yield, capital expenditure, SGA, analyst coverage or legal origin ${ }^{10}$ are related to the choice of the targets, while controlling for year, industry, and geographic fixed effects. The marginal effects exhibited in column (1) of Table 3 indicate that our matching procedure was effective, as only a few of the above variables (smaller size, higher stock market performance, higher product market share, and more analyst coverage) help predict which firms are targeted. The results also show that the asset manager does not generally target companies multiple times, which suggests that engagements are evaluated and started on a per-case basis and that the activist does not have "favorite" targets.

In column 2 of Table 3, we add the percentage of shares owned by the activist prior to the engagement, whether the firm is independent (does not have a major blockholder controlling at least $25 \%$ of the equity), the corporate governance index, the country ESG sentiment, and the aggregate ESG score. For the sample of all engagement cases, we find that firms with lower ESG scores but in high-ESG-sentiment countries are more likely to be targeted. Economically, the marginal likelihood of being targeted, -0.160 ( $z$-statistic of - 1.93), implies that a standard deviation decrease in the ESG score (of 23.8) is associated with a $3.81 \%$ increase in likelihood, an increase of over $10 \%$ over the unconditional probability. This shows that the activist tends to target companies with more room for improvement in their ESG practice. Ex ante, it seems reasonable to expect greater scope for ESG improvements at firms with low ESG scores.

In the remaining columns of Table 3, we separately estimate the likelihood of being engaged in the environmental (columns 3-4), social (columns 5-6), and governance (columns 7-8) areas. We find that the results from columns 1-2 largely hold, although, in case of the governance dimension,

\footnotetext{
$\overline{10}$ We present detailed breakdowns of legal origin by country in "Appendix D", following Liang and Renneboog (2017). In our analyses, we concentrate on common law vs. civil law, as ESG is shown to be the most varied across this separation.
} 
Table 3 Analysis of targeting by engagement themes

This table reports the marginal effects obtained from probit regressions on the probability of targeting relative to a matched sample, where the dependent variable is 1 if a company if targeted and 0 otherwise. The first two columns report regression results for the whole sample of engagements (1-2), while the second, third, and fourth sets of columns refer to environmental (3-4), social (5-6) and governance (7-8) cases, respectively. Marginal effects are evaluated at the mean of the respective independent variable. The variable "ESG score" is the equal ESG rating for the full sample and the corresponding score for each specific engagement theme, expressed as a percentage. Standard errors are clustered at the firm level. The matching sample is determined by Mahalanobis score matching on industry, size, market-to-book, ESG, and ROA. Variable definitions are provided in the Appendix

\begin{tabular}{|c|c|c|c|c|c|c|c|c|}
\hline & \multicolumn{2}{|c|}{ Full sample } & \multicolumn{2}{|c|}{ Environmental } & \multicolumn{2}{|l|}{ Social } & \multicolumn{2}{|l|}{ Governance } \\
\hline & (1) & (2) & (3) & (4) & (5) & (6) & (7) & $(8)$ \\
\hline Log total assets & $-0.031 * *$ & 0.025 & -0.008 & 0.036 & $-0.030^{*}$ & 0.02 & $-0.060^{* *}$ & $0.036^{* *}$ \\
\hline Tobin's Q & 0.001 & 0.002 & 0.023 & 0.029 & -0.003 & -0.009 & -0.029 & $-0.068 * * *$ \\
\hline Sales growth & -0.056 & -0.072 & -0.062 & -0.074 & -0.076 & -0.133 & $0.176^{*}$ & -0.063 \\
\hline BHR over 12 months & $0.077 * * *$ & $0.096^{* * *}$ & 0.038 & 0.023 & $0.085^{* * *}$ & $0.130 * * *$ & $0.142 * *$ & $0.247 * * *$ \\
\hline ROA & 0.253 & 0.097 & 0.252 & 0.076 & 0.285 & 0.029 & -0.208 & -0.163 \\
\hline Sales market share & $3.899 * * *$ & $2.752 * * *$ & $3.272 * * *$ & $2.412 * * *$ & $4.590 * * *$ & $3.193 * * *$ & $3.785 * * *$ & $1.760 * *$ \\
\hline Cash holding & -0.097 & 0.066 & 0.105 & 0.124 & -0.211 & -0.131 & 0.1 & $0.343 * *$ \\
\hline Book leverage & 0.078 & 0.038 & 0.114 & 0.055 & -0.019 & 0.041 & 0.196 & $-0.212 * * *$ \\
\hline Dividend yield & 0.547 & 0.953 & 0.593 & $1.200 *$ & 0.345 & 0.922 & $2.907 * *$ & $1.015^{*}$ \\
\hline CapEX & 0.103 & 0.271 & 0.278 & 0.391 & -0.076 & -0.333 & -0.902 & $0.930 * *$ \\
\hline Amihud ILLIQ & -0.006 & $-0.544 * *$ & -0.05 & $-0.430 * *$ & 0.021 & -0.603 & -4.221 & -3.022 \\
\hline Analysts & $0.012 * * *$ & $0.010 * * *$ & $0.013 * * *$ & $0.010 * * *$ & $0.009 * * *$ & $0.014 * * *$ & $0.014 * * *$ & $0.007 * * *$ \\
\hline SGA & 0.044 & 0.165 & 0.12 & 0.181 & -0.122 & 0.054 & $0.481 * *$ & $0.488 * * *$ \\
\hline Common law & $-0.071 * *$ & -0.028 & 0.003 & 0.027 & $-0.064^{*}$ & -0.041 & $-0.219 * * *$ & $0.119 *$ \\
\hline Previous engments & $-0.023 * *$ & $-0.030 * * *$ & $-0.032 * *$ & $-0.052 * * *$ & $-0.021^{*}$ & $-0.025^{* *}$ & -0.018 & $-0.009^{*}$ \\
\hline Holding of engager & & 3.027 & & 20.871 & & 1.118 & & 6.443 \\
\hline Independent company & & -0.005 & & -0.064 & & -0.008 & & 0.039 \\
\hline ESG sentiment & & $0.008 * * *$ & & $0.008 * * *$ & & 0.003 & & $0.017 * * *$ \\
\hline Entrenchment index & & -0.025 & & -0.031 & & -0.062 & & $0.124 * *$ \\
\hline ESG score & & $-0.160 * * *$ & & & & & & \\
\hline E score & & & & -0.038 & & & & \\
\hline S score & & & & & & $-0.161 * *$ & & \\
\hline G score & & & & & & & & $-0.419 * * *$ \\
\hline Year dummy & Yes & Yes & Yes & Yes & Yes & Yes & Yes & Yes \\
\hline Industry dummy & Yes & Yes & Yes & Yes & Yes & Yes & Yes & Yes \\
\hline Geographic dummy & Yes & Yes & Yes & Yes & Yes & Yes & Yes & Yes \\
\hline Pseudo $R^{2}$ & 0.12 & 0.23 & 0.13 & 0.20 & 0.10 & 0.24 & 0.42 & 0.75 \\
\hline$N$ & 2567 & 2028 & 1127 & 900 & 1090 & 816 & 346 & 304 \\
\hline
\end{tabular}

$*, * *$ and $* * *$ indicate statistical significance at the $10 \%, 5 \%$, and $1 \%$ levels, respectively

more targeting occurs for companies that have lower potential growth opportunities but are profitable (in terms of share price performance) and have a high Entrenchment index. ${ }^{11}$

\footnotetext{
11 As a robustness test, we repeat the analysis in the first panels of Table 3 for varying levels of engagement, whereby the ordering refers to differences in the effort level in engagement. Specifically, we estimate ordered probit models in which the dependent variable is one for engagements triggered for reasons of transparency ("light engagements"), two for engagements triggered for reorganization reasons ("strong engagements"), and zero in cases with no engagement. In unreported results, we find that our previous findings are robust to ordering and that, for the strong engagements, the coefficients are larger (in absolute terms).
}

Overall, the results indicate that the activist targets visible firms, with large market shares, and in which the activist holds a larger share stake. The tests on the whole sample indicate that the activist does concentrate on firms in the poorest ESG performance category. ${ }^{12}$

\footnotetext{
12 We repeat the analysis of Table 3 with geographical segmentation between North American, European, and other domiciled companies. The analysis is presented in "Appendix D", Table 11. We find that the results are qualitatively similar.
} 


\section{Engagement Success}

In this section, we consider the drivers of "successful" engagements. As we noted above, success is not determined by a realization of value triggered by the adoption of the activist's requirements, nor by the amount of effort the target exerts to meet the activist's demands. It depends solely on whether the target complies with whatever the activist set forth as the ex ante demand. Table 4 explores possible drivers of successful engagements, which include (in addition to the variables in Table 3) indicator variables for whether or not the activist requests a reorganization effort (captured by the variable Reorganization) rather than just more transparency, whether or not the engagement was conducted jointly with other activists (Joint targeting), whether the activist targeted top executives in the target versus lower-level managers or non-executive directors (Contacted executives), the number of contacts over the course of the engagement (Number of contacts), and, finally, whether any previous engagement involving the firm was successfully concluded (Success streak). ${ }^{13}$

The results in column 1 reveal that, on average, cases where the activist requests that the target make significant changes in terms of board or asset restructuring or a change in ESG-related operations are significantly less likely to lead to successful case closure. The coefficient of Reorganization, -0.163 , suggests that such far-reaching requests have a 16.3\% lower likelihood of being successfully closed, compared to an overall success rate of $60 \%$. This is not surprising, as the effort level required of firms is much higher in reorganization engagements. In general, it is easier to achieve "success" in transparency cases, but whether these cases can generate significant value-value that is subsequently reflected in the stock price or the accounting performance-is questionable. In contrast, reorganization cases may be more likely to lead to value enhancement, but they are also harder to achieve, as they require more substantial, farther-reaching corporate decisions, which the management may be reluctant to make.

Returning to column 1 of Table 4, we find that the eventual success of the engagement is higher if the activist jointly targets a company with other activists; however, this finding is driven by engagements in the social domain. The success rate is not higher if executives rather than non-executives are the engager's main contact at the target, if the number of contacts between the activist and the firm is higher, or if the firm is more visible (as indicated by a larger number of analysts following the firm). Companies that previously

\footnotetext{
13 We repeat the analysis of Table 4 with geographical segmentation between North American, European, and other domiciled companies. The analysis is presented in "Appendix D", Table 12.
}

implemented activist-requested changes are more likely to comply with future requests, albeit mainly in environmental engagements. Targets are also more likely to comply with activist requests when their sales growth is lower. In particular, the coefficient on Sales Growth of -0.357 indicates that a standard deviation decrease in sales growth (of 0.290) is associated with a $10.4 \%$ increase in the likelihood of success. The coefficient of $S G A$ is significant and consistently positive across specifications for the full sample, as well as for both environmental and social engagements. This suggests that companies with a large overhead cost base are significantly more compliant (by up to $14.7 \%$ for social cases). One explanation for this is that companies with a high level of SGA can rechannel their non-production costs towards ESG activities. An alternative explanation is that they deem it more relevant to spend on ESG rather than, for example, advertising, as they attempt to increase consumer awareness (Servaes \& Tamayo, 2013).

Next, column 2 examines additional variables capturing governance and ESG aspects. We find no persistent relation between engagement success and the proportion of the shares owned by the activist and the increases in this equity stake during the engagement process ("Holding increase"), or between engagement success and the target's corporate governance (as proxied by the aggregate index of shareholder rights provisions-the entrenchment index). However, we do find that engagement success is more likely for firms with a higher ESG score prior to engagement. The marginal likelihood of 0.448 means that a standard deviation increase in ESG ratings is associated with a $10.7 \%$ increase in the probability of success. This is consistent with the ex ante ESG score indicating how much firms care about ESG issues, and also with the notion that firms with a stronger ESG track record have the necessary ESG resources and know-how largely in place, such that compliance does not require a large departure from existing practices. In contrast, ESG sentiment, captured by the average ESG score within the country, does not influence engagement outcomes. Together, these findings suggests that it is the activist's efforts, not other external factors, that propagate success.

It is possible that the activist is more likely to target firms where the activist anticipates that a successful engagement can be more easily achieved. To control for this and other potential selection issues with the selection equation model (2) of Table 3, we estimate, as a robustness analysis, a twostage Heckman model. We find that the above results in Table 4 carry through, and that selection does not appear to be an issue (as the inverse Mills ratio is insignificant in all our specifications). ${ }^{14}$

\footnotetext{
${ }^{14}$ We do not present the results here for the sake of brevity, but they are available upon request.
} 
Table 4 Analysis of success

This table reports the marginal effects obtained from linear probability regressions on the probability of success. The dependent variable equals 1 if the engagement is successful and 0 otherwise. The first two columns report regression results for the whole sample of engagements (1-2), while the second, third, and fourth sets of columns refer to environmental (3-4), social (5-6), and governance (7-8) cases, respectively. Standard errors are clustered at the firm level. The dummy "Reorganization" takes the value 1 for reorganization cases and 0 otherwise. The dummy variable "Joint targeting" equals one for cases where the engager contacts the company with a group of other activists. The variable "Contacted executives" is 1 if executive management is contacted and 0 otherwise. "Number of activities" and "Success streak" refer to the number of contacts per case and the number of previous successful cases with the company. Other variable definitions are provided in the Appendix

\begin{tabular}{|c|c|c|c|c|c|c|c|c|}
\hline & \multicolumn{2}{|l|}{ Full sample } & \multicolumn{2}{|c|}{ Environmental } & \multicolumn{2}{|l|}{ Social } & \multicolumn{2}{|l|}{ Governance } \\
\hline & (1) & (2) & (3) & (4) & $(5)$ & (6) & (7) & $(8)$ \\
\hline Reorganization & $-0.163 * * *$ & $-0.144 * *$ & $-0.434 * * *$ & $-0.335^{* *}$ & -0.017 & 0.014 & 0.124 & 0.170 \\
\hline Joint targeting & $0.094 *$ & 0.039 & 0.081 & 0.021 & $0.128 *$ & 0.106 & -0.246 & -0.229 \\
\hline Contacted executives & $-0.111 * *$ & -0.090 & 0.080 & 0.006 & $-0.267 * * *$ & $-0.194 * *$ & -0.147 & -0.054 \\
\hline Number of contacts & 0.008 & 0.006 & 0.008 & 0.010 & -0.023 & -0.020 & 0.015 & 0.026 \\
\hline Success streak & 0.010 & 0.010 & $0.057 *$ & 0.048 & -0.025 & -0.010 & -0.011 & -0.033 \\
\hline Log total assets & 0.020 & -0.036 & 0.028 & -0.038 & 0.035 & 0.001 & $0.086^{* *}$ & 0.075 \\
\hline Tobin's Q & -0.030 & -0.023 & -0.038 & -0.063 & -0.042 & -0.024 & -0.066 & $-0.284 * * *$ \\
\hline Sales growth & $-0.357 * * *$ & $-0.333 * * *$ & $-0.380^{* *}$ & -0.242 & -0.154 & -0.260 & $-0.908 * * *$ & $-0.720 * *$ \\
\hline BHR over 12 months & 0.036 & -0.019 & 0.026 & 0.024 & 0.042 & 0.070 & -0.161 & $-0.597 * * *$ \\
\hline ROA & -0.342 & -0.596 & -0.373 & -0.103 & 0.366 & -0.404 & 0.699 & $4.238 * *$ \\
\hline Sales market share & 1.357 & $1.903 * *$ & 0.099 & 0.240 & 1.387 & 2.071 & -1.840 & $-5.341 * *$ \\
\hline Cash holding & -0.392 & $-0.804 * *$ & $-0.980 * *$ & $-1.265^{* *}$ & -0.419 & $-0.854^{*}$ & 0.331 & -0.222 \\
\hline Book leverage & 0.040 & -0.103 & -0.024 & 0.043 & 0.223 & -0.088 & -0.077 & 0.290 \\
\hline Dividend yield & 0.230 & 0.490 & -0.182 & 0.808 & 0.634 & 1.001 & -0.545 & -6.120 \\
\hline CapEX & -0.258 & 0.515 & -0.763 & -0.069 & 1.200 & $2.668 * *$ & 0.262 & -1.169 \\
\hline Amihud ILLIQ & -0.011 & 0.299 & $0.114^{*}$ & -0.127 & -0.025 & $1.501 * *$ & -9.996 & $-30.889 * *$ \\
\hline Analysts & 0.001 & -0.001 & -0.006 & $-0.011 * *$ & $0.008^{*}$ & 0.005 & -0.006 & 0.008 \\
\hline SGA & $0.725 * * *$ & $0.597 * * *$ & $0.675^{* *}$ & $0.748 * *$ & $0.795 * * *$ & $0.828 * * *$ & 0.291 & -0.475 \\
\hline Common law & -0.008 & -0.031 & 0.025 & -0.047 & -0.089 & -0.040 & 0.657 & 0.405 \\
\hline Toehold & & 0.008 & & -0.013 & & 0.005 & & $0.027 * *$ \\
\hline Toehold increase & & -0.036 & & $-0.187 * * *$ & & 0.047 & & $0.275^{* *}$ \\
\hline Independent company & & 0.111 & & 0.035 & & 0.138 & & -0.250 \\
\hline Entrenchment index & & 0.033 & & 0.176 & & -0.059 & & -0.243 \\
\hline ESG sentiment & & 0.000 & & -0.004 & & 0.003 & & $-0.020 *$ \\
\hline ESG score & & $0.366^{* *}$ & & & & & & \\
\hline E score & & & & $0.484 * * *$ & & & & \\
\hline S score & & & & & & 0.191 & & \\
\hline G score & & & & & & & & -0.217 \\
\hline Year dummy & Yes & Yes & Yes & Yes & Yes & Yes & Yes & Yes \\
\hline Industry dummy & Yes & Yes & Yes & Yes & Yes & Yes & Yes & Yes \\
\hline Geographic dummy & Yes & Yes & Yes & Yes & Yes & Yes & Yes & Yes \\
\hline Adjusted $R^{2}$ & 0.25 & 0.24 & 0.24 & 0.26 & 0.34 & 0.35 & 0.32 & 0.37 \\
\hline$N$ & 616 & 471 & 272 & 218 & 263 & 185 & 81 & 68 \\
\hline
\end{tabular}

$*, * *$ and $* * *$ indicate statistical significance at the $10 \%, 5 \%$, and $1 \%$ levels, respectively

When we analyze the outcome of engagement by ESG theme in columns 3-8 of Table 4 , we find that reorganization requests are less likely to be successful, and that previous successful engagements matter for the subset of engagements related to environmental issues but not for social or governance engagements. For environmental engagements, large cash holdings are associated with a reduced probability that the case is closed successfully, perhaps because large cash holdings occur at corporations that are less dependent on external capital markets and that, accordingly, are less interested in good investor relationships. For the subset of social engagements, those at firms with a larger market share are more likely to be successful, which suggests that market leaders in their industry are more open to 
investor engagement or are more worried about potential negative media stories. The sensitivity to the engagement is also larger for firms that have lower sales growth, possibly because lower growth puts them under pressure from investors. Finally, governance engagements are more likely to be successful at firms with low buy-and-hold returns over the past year. This finding is strongly statistically significant once we control for the entrenchment index and ESG characteristics in column (8). However, lower buy-and-hold returns are not related to a higher likelihood of success for environmental or social engagements. This suggests that corporations deem investor concerns more relevant when they have performed relatively poorly in the stock market, but primarily when they face governance activism (in which case they may hope to forestall more significant shareholder activism).

\section{Analysis of Performance After Engagement}

Implementing or increasing CSR can increase firm value several ways, as pro-social behavior can be rewarding for various stakeholders, shareholders, and management (Baron, 2008; Bénabou \& Tirole, 2006). First, higher ESG standards can increase consumer loyalty through product quality signaling, leading to higher market share and higher and less volatile profits (Albuquerque et al., 2019). Second, employee satisfaction fosters productivity and efficiency, also leading to higher profits (Edmans, 2011; Edmans, 2012). Third, corporate social responsibility can attract a shareholder base that has long-term investment goals, reducing pressure on management to generate short-term profits and allowing for investments that yield returns over a longer time horizon (Gaspar et al., 2013). Fourth, improved governance standards indicate better management practices and result in higher future performance (Ferrell et al., 2016). Finally, investments in CSR could be similar to paying an insurance premium to avoid rare events that could harm a firm and which are not priced yet (Hong et al., 2015; Lins et al., 2017).

We first test the impact of engagements on the operations and characteristics of target firms. We estimate differencesin-differences (DD) specifications (Eqs. 2and 3) in which the dependent variables are market-based measures of performance (Tobin's Q), accounting-based measures of performance (ROA, operating expenses, SGA, sales growth, profit margin, asset turnover), and measures of sales market share, investments (CapEx), ownership (long-term holdings, toehold stake of the activist), ESG performance (ESG ratings; environmental, social, governance scores), corporate governance (entrenchment index), changes in capital structure (equity and debt issuance), and visibility (analysts following). We use two treatments, the successful completion of the engagement case (Eq. 2) and the engagement treatment irrespective of subsequent success (Eq. 3):

$y_{i, t}=\alpha+$ Bpost $_{t}+\gamma$ success $_{i}+$ spost $_{t} \times$ success $_{i}+$ vcontrols $_{i, t}+\epsilon_{i, t}$,

$y_{i, t}=\alpha+$ Bpost $_{t}+$ rengaged $_{i}+$ spost $_{t} \times$ engaged $_{i}+$ vcontrols $_{i, t}+\epsilon_{i, t}$,

where Post is an indicator variable that equals one for the 1 -year period following the successful closure of a case, and zero otherwise (Eq. 2), or for the 2-year period after the engagement, and zero otherwise (Eq. 3). The latter case captures the typical duration of the engagements. Equation (2) is estimated for the sample of engaged companies (both successful and unsuccessful outcomes), whereas Eq. (3) is estimated for the sample of both engaged and non-engaged matched firms.

We apply the same methodology on various subsamples: the reorganization-oriented engagements, the quartiles of firms with the lowest and highest ESG scores (measured prior to engagement), and the environmental-, social-, and governance-oriented cases. Furthermore, we split the sample into low and high governance and low and high visibility groups. The split is based on the median of the E-index and the analyst base, respectively. Finally, we separate companies that have no shareholder controlling more than 5\% (Independent company) from companies that do (Controlling shareholder). In all these specifications, the vector Controls includes leverage, size, tangibility of assets, and time and industry fixed effects. ${ }^{15}$ We cluster standard errors at the firm level.

For the sake of brevity, we only report the $\delta$ coefficients in Table 5, where each coefficient comes from a separate regression. In Panel A, we report the $\delta$ coefficients for the evaluation of success for all engagement cases (column 1) and for the 12 subsamples. The results indicate that, on average, accounting performance does not significantly change following a successful engagement. This is in line with Klein and Zur (2011) results showing that hedge fund activism does not improve accounting performance. And while Di Giuli and Kostovetsky (2014) show that a higher level of ESG is detrimental to future profitability (especially through increased costs), we find that this claim is unsubstantiated in our sample.

Sales growth, in contrast, improves by $3-22 \%$ on average after successful engagements. This improvement is seen across all subsamples except social engagements. Given the typical sales growth of $10.1 \%$ in the year preceding engagement, the overall jump of $7.6 \%$ is quite meaningful not only statistically but also economically.

\footnotetext{
15 In the analysis of Tobin's Q, we also include ROA, CapEx, and sales growth.
} 
The coefficients on the ESG performance ratings confirm that successful engagements lead to higher ESG scores for the targets with the ex ante weakest ESG ratings (the lowest quartile). The results suggest that if a case is closed successfully with an ex ante poorly rated company, the ESG rating, on average, increases by 10.6 , which is a significant boost of $13.7 \%$ compared to the mean. This growth is most pronounced for environmental ratings, where we observe an $18.6 \%$ gain relative to the initial rating.

It is possible that an activist's targeting of a firm generates an effect even if the activist does not attain its specific goals for the engagement. To investigate this possibility, we turn to panel B of Table 5, where we report the DD coefficients of an analysis where the treatment effect is engagement and the non-treated sample consists of matched nonengaged firms. As before, we study the changes in corporate and ESG performance as well as other firm characteristics for the full sample and a set of subsamples. We find that the engagement, in itself, has little impact on the ex post accounting performance (column 1) or any other firm characteristic (with the exception of the market share, which is a little lower). For example, the increases in sales growth that we document for successful cases do not occur for unsuccessful ones.

The subsamples of firms within the lowest versus highest (ex ante) ESG quartiles yield some interesting results. For example, the mere fact of engaging low ESG targets triggers significant increases in the targets' ESG scores. The overall score and the subscores on the E, S, and G aspects all augment, as does the economic outlook sub-score (which proxies for shareholder and customer loyalty). So, the mere engagement, independent of outcome, triggers changes in the ESG profile of the target, which are, in turn, picked up by independent ESG evaluation providers. For the firms in the highest ex ante ESG quartile, we observe the inverse, as all of the ESG scores go down after the engagement. This could be the result of an information revelation process: if, after conducting research, the activist correctly identifies companies with a potential for improvement in one of the ESG dimensions, then subsequent ESG ratings should reflect this new information. The adjusted ESG scores thus incorporate the potential ESG problem, driving down the score. Together, these results imply that research and engagement activity brings new information to market actors and helps reveals companies' ESG practices. The new information might show that previously low-rated companies are not "lost cases," or that recent best-performers still have room for improvement. As the activist engages companies, the rating agency generally seems to realize, over the course of the engagement, that previous scores did not incorporate all of the activist's concerns, i.e., that engaged companies still had key ESG points to improve on. ${ }^{16}$

Our results also indicate that there are significant postengagement changes in how firms attract capital. We find that after an engagement (Panel B), engaged firms with low corporate governance (a high E-index, capturing weak shareholder rights) issue more debt than non-engaged firms. The same occurs for engaged firms with high visibility and for engaged firms with widely held ownership. The lowcorporate-governance finding is especially important, as it suggests that ESG engagement could lead to improved governance and reduced agency problems. We next turn to the effect of successful versus non-successful closure of ESG engagement (Panel A). After a successful engagement, we observe more debt issues in firms with low corporate governance (high E-index) and firms with low visibility (low analyst coverage). This suggests that a successful engagement could induce trust in the corporation, such that the firm can more easily issue debt (possibly induced by a lower expected cost of capital). Taken together, our results tie in with the Boubakri et al. (2018) evidence that shareholders and bondholders react differently to externally influenced corporate actions.

\section{Returns to Engagement}

In this section, we assess two measurements of stock performance during and after the engagement: buy-and-hold returns (BHRs), which are raw, unadjusted cumulative returns, and cumulative abnormal returns (CARs), which are returns corrected for exposure to the global market, size, book-to-market, and momentum Fama-French-Carhart return factors. We use stock return data from Datastream and download our factor data from the website of Kenneth French.

In Table 6, we report BHRs over the engagement period and by the ex post outcome for all of the firms in our sample. Additionally, we report the contemporaneous returns of matched firms. Since engagement sequences vary in length (with a mean of about 20 months), we calculate annualized returns. We calculate the BHRs over the engagement period and then annualize to make the returns comparable. For matched firms, we annualize over the same horizon as for their respective targeted counterparts. The table reports returns for the entire sample, for low and high ESG firms, for reorganizations, and by ESG topic. Two main results

\footnotetext{
${ }^{16}$ In unreported results, we define the pre- and post-periods of Eqs. 2 and 3 in various ways. Specifically, we move the cutoffs to $1-3$ years after the start and to 1-3 years after the completion of engagements. The results are qualitatively similar to the ones presented here.
} 


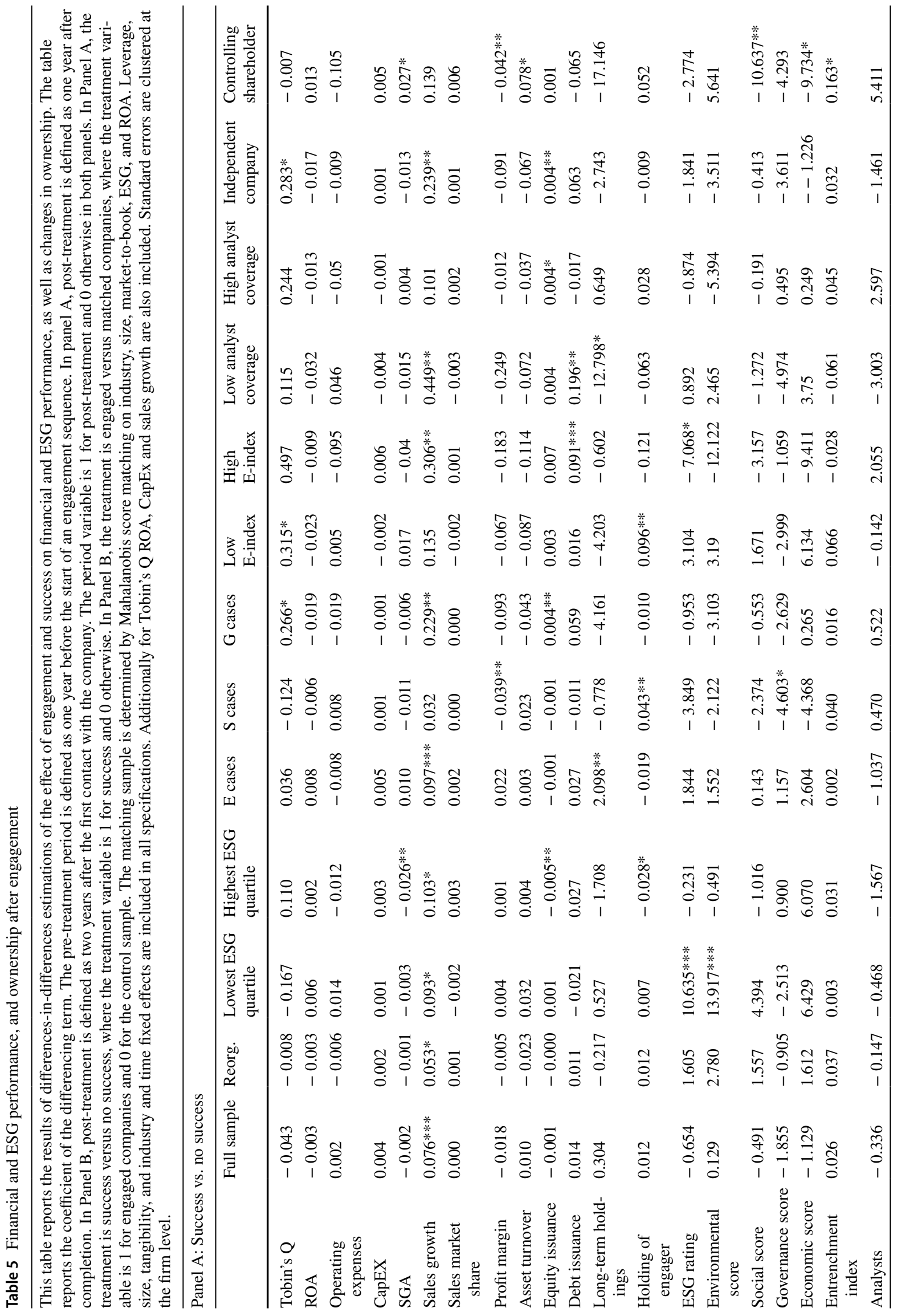




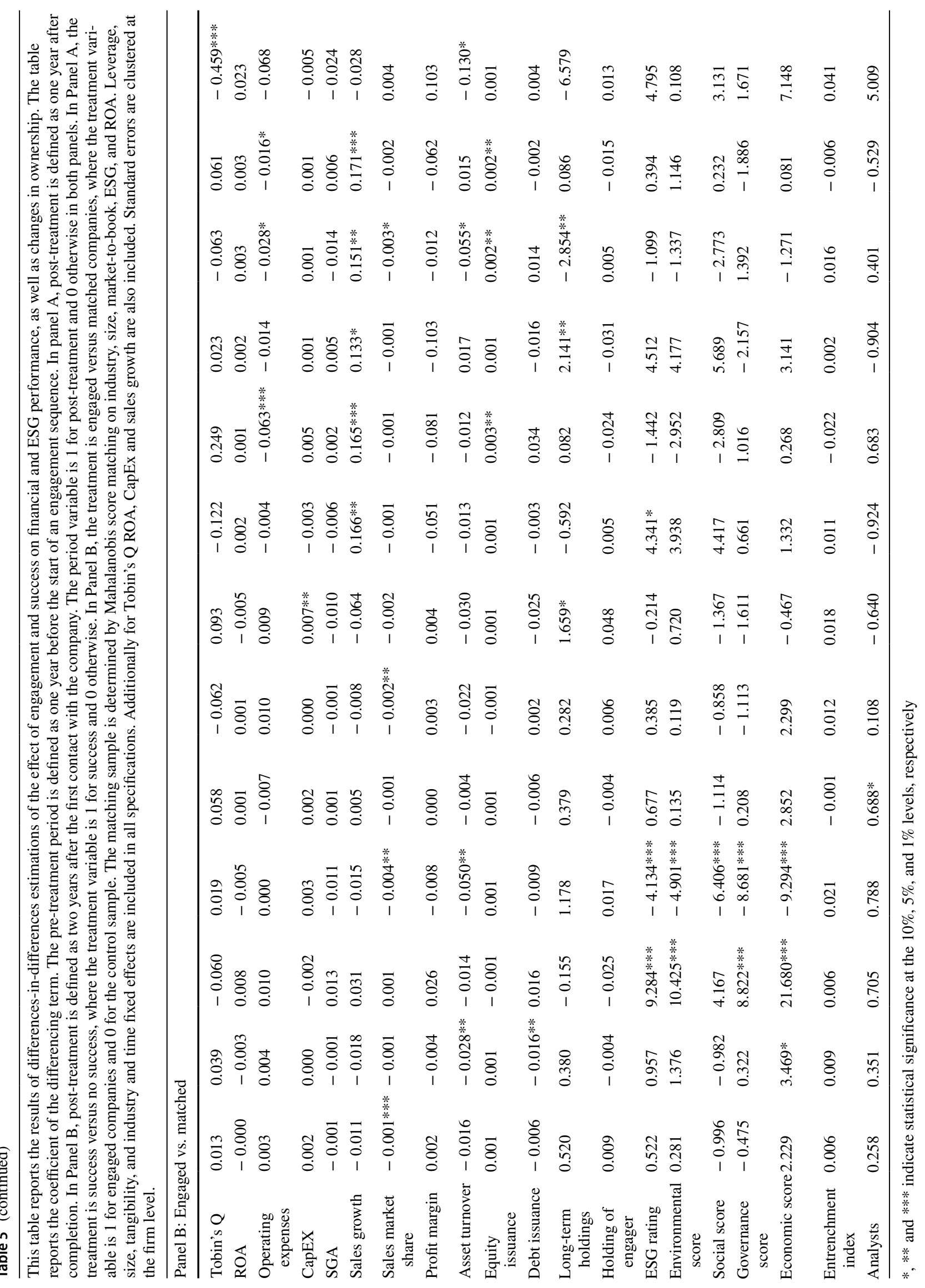




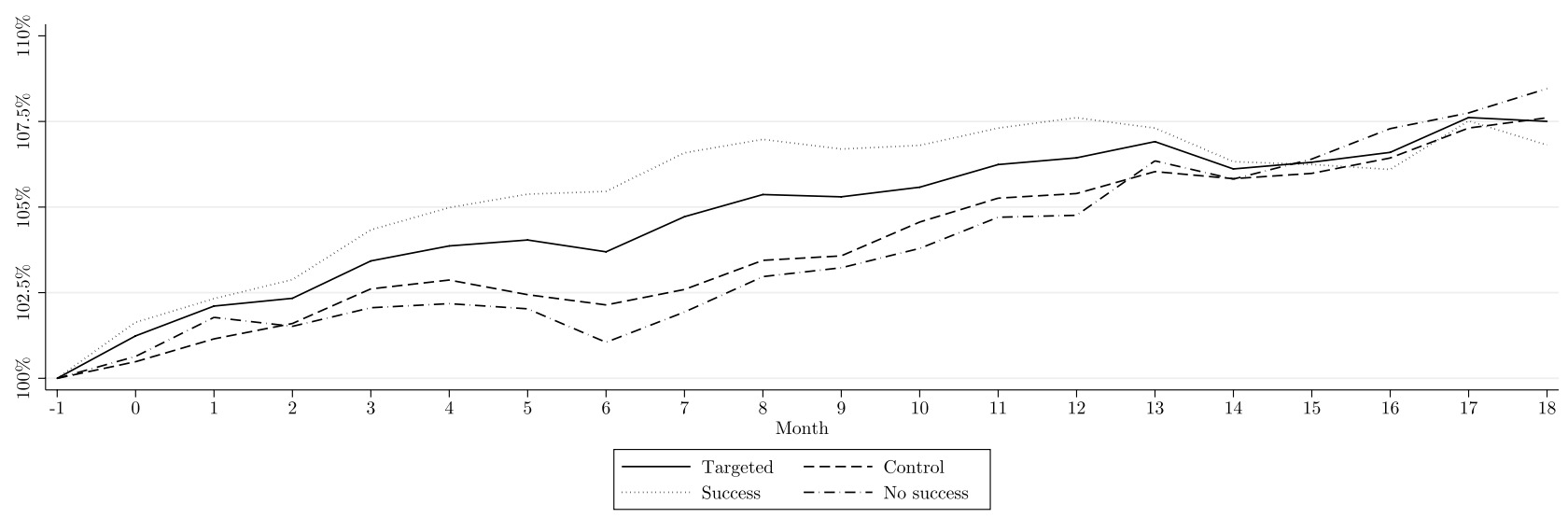

Fig. 2 Buy-and-hold returns after completion. The figure shows buy-and-hold returns for an equally weighted portfolio of engaged companies, as well as for control firms. The portfolios are formed at the completion of engagements

emerge from this table. First, targeted firms always realize higher returns over the engagement period than their matched counterparts (with the exception of high ESG firms and firms targeted for social topics). On average, engaged firms have a return of $14.5 \%$, compared to $11.9 \%$ for the control group in the same period, but the difference is not statistically significant. Engaged firms perform significantly better when they are in the lowest ESG quartile, are subject to reorganization, or are engaged for environmental reasons. Second, using the ex post measure of success, we find that firms that are engaged (eventually) successfully earn returns during the process that are not statistically different from the returns of unsuccessful cases.

In Table 7, we report BHRs in the month around the completion of the engagement (distinguishing between successful versus unsuccessful completion, and control firms) and over time windows of 6 and 12 months following the end of the engagement. We find that, on average, BHRs are small but positive and statistically significant in the month following the closure of a case (at 1.2\%). These positive returns stem from successfully closed cases, which generated BHRs of $1.6 \%$; cases that were not successfully closed do not generate any significant return. Over the period of six months after their completion, successful cases generate returns of 5.5\%, while unsuccessful cases incur insignificant price movement (1.1\%). Extending the time window to one year, we find large positive returns for both successful and unsuccessful cases, but the difference between the successful and unsuccessful cases is now insignificant.

We re-estimate these BHRs over the same time windows for different subsamples and also report the results in Table 7. The target subsamples with the lowest ESG scores ex ante generate $4.7 \%$ higher returns over a six-month window and $6.8 \%$ higher returns over a one-year window, relative to the control firms. Successfully and unsuccessfully engaged target firms do not show any significant return difference over any time window. For the ex ante highestrated ESG firms, the return difference with the control firms is immediate (in the first month after ending the engagement); again, this finding does not depend on the outcome of the engagements.

Reorganizations do not perform better, in general, after the engagement than control firms do. Although successful reorganizations yield BHRs of $2.5 \%$ in the month of the engagement completion and $5.4 \%$ over a 1-year post-engagement window, unsuccessful reorganizations yield BHRs that are close to zero. When we partition the engagement files by ESG dimension, we find that it is mainly the firms that are engaged for environmental reasons that significantly outperform the control firms (by 3\% over a year). Over the time window of 6 months after the end of the engagement, successful environmental engagements outperform unsuccessful environmental engagements by $5.9 \%$, and successful social engagements outperform unsuccessful social engagements by $3.6 \%{ }^{17}$

In Fig. 2, we depict the mean BHR of equally weighted portfolios of engaged companies, where the portfolios were created one month prior to the event month and the returns are calculated over the subsequent 18 months. The return difference between successful and unsuccessful cases is highest for the period 6-12 months following the completion. Figures depicting the mean BHR over 18 months after the completion of the engagement for the subsamples of engaged North American, European, and

\footnotetext{
$\overline{17}$ We repeat the analysis of Table 7 for the subsamples of North American, European, and Other cases. The results are largely in line with the ones reported for the overall sample (although some subsamples, partitioned based on geography and (un)successfulness, become small). The results are available upon request.
} 
Table 6 Buy-and-hold portfolio returns over engagements

The table presents mean annualized buy-and-hold returns over engagements for various subsamples. For each subsample, returns are calculated for the entire subsample, for successful and unsuccessful engagements, and for their respective control groups. The table reports whether the mean is equal to zero and the difference between successful and unsuccessful cases and the control group. The matching sample is based on Mahalanobis score matching on industry, size, market-to-book, ESG, and ROA. We report t-statistics for differences

\begin{tabular}{|c|c|c|c|c|c|c|c|c|c|c|}
\hline & (1) & (2) & (3) & (4) & (5) & (6) & (7) & (8) & (9) & (10) \\
\hline & Targeted & Control & Success & No success & Success - control & No success - control & 1 v. 2 & 3 v. 4 & 3 v. 5 & 4 v. 6 \\
\hline \multicolumn{11}{|c|}{ All cases } \\
\hline Mean & $0.145 * * *$ & $0.119 * * *$ & $0.127 * * *$ & $0.171 * * *$ & $0.116 * * *$ & $0.123 * * *$ & 0.026 & -0.045 & 0.011 & 0.048 \\
\hline Obs. & 846 & 2544 & 509 & 337 & 1530 & 1014 & 3390 & 846 & 2039 & 1351 \\
\hline \multicolumn{11}{|c|}{ Lowest ESG quartile } \\
\hline Mean & $0.115 * *$ & 0.009 & 0.137 & $0.098 * *$ & 0.007 & 0.011 & $0.106^{* * *}$ & 0.039 & $0.130 * *$ & $0.087 * *$ \\
\hline Obs. & 176 & 525 & 78 & 98 & 234 & 291 & 701 & 176 & 312 & 389 \\
\hline \multicolumn{11}{|c|}{ Highest ESG quartile } \\
\hline Mean & $0.117 * * *$ & $0.203 * * *$ & $0.090 * *$ & $0.221 *$ & $0.149 * * *$ & $0.407 *$ & -0.086 & -0.132 & -0.060 & -0.185 \\
\hline Obs. & 165 & 495 & 131 & 34 & 393 & 102 & 660 & 165 & 524 & 136 \\
\hline \multicolumn{11}{|c|}{ Reorganization } \\
\hline Mean & $0.147 * * *$ & $0.102 * * *$ & $0.115^{* *}$ & $0.172 * * *$ & $0.090 * * *$ & $0.111 * * *$ & $0.045^{*}$ & -0.057 & 0.025 & $0.061 *$ \\
\hline Obs. & 435 & 1314 & 190 & 245 & 576 & 738 & 1749 & 435 & 766 & 983 \\
\hline \multicolumn{11}{|c|}{ Environmental } \\
\hline Mean & $0.151 * * *$ & $0.079 * * *$ & $0.108 * * *$ & $0.199 * *$ & $0.102 * * *$ & $0.052 * * *$ & $0.072 * *$ & -0.091 & 0.006 & $0.147 * * *$ \\
\hline Obs. & 358 & 1068 & 190 & 168 & 570 & 498 & 1426 & 358 & 760 & 666 \\
\hline \multicolumn{11}{|l|}{ Social } \\
\hline Mean & $0.141 * * *$ & $0.163 * * *$ & $0.160 * * *$ & $0.110 * *$ & $0.139 * * *$ & $0.201 * * *$ & -0.023 & 0.050 & 0.022 & -0.091 \\
\hline Obs. & 366 & 1113 & 223 & 143 & 675 & 438 & 1479 & 366 & 898 & 581 \\
\hline \multicolumn{11}{|c|}{ Governance } \\
\hline Mean & $0.138 * *$ & $0.101 * * *$ & 0.086 & $0.331 * *$ & $0.090 * * *$ & $0.141 * *$ & 0.037 & -0.245 & -0.004 & $0.190^{*}$ \\
\hline Obs. & 122 & 363 & 96 & 26 & 285 & 78 & 485 & 122 & 381 & 104 \\
\hline \multicolumn{11}{|c|}{ Low E-index } \\
\hline Mean & $0.128 * * *$ & $0.068 * * *$ & $0.071 * * *$ & $0.235 * * *$ & $0.037 * * *$ & $0.126^{* * *}$ & $0.060 * * *$ & -0.164 & $0.034 *$ & $0.109 * * *$ \\
\hline Obs. & 529 & 1584 & 347 & 182 & 1041 & 543 & 2113 & 529 & 1388 & 725 \\
\hline \multicolumn{11}{|c|}{ High E-index } \\
\hline Mean & $0.156^{* * *}$ & $0.171^{* * *}$ & $0.146^{* * *}$ & $0.180 * *$ & $0.189 * * *$ & $0.125 * * *$ & -0.015 & -0.034 & -0.043 & 0.056 \\
\hline Obs. & 112 & 336 & 80 & 32 & 240 & 96 & 448 & 112 & 320 & 128 \\
\hline \multicolumn{11}{|c|}{ Low analyst coverage } \\
\hline Mean & $0.156 * * *$ & $0.131 * * *$ & $0.121 * * *$ & $0.195 * * *$ & $0.078 * * *$ & $0.190 * * *$ & 0.025 & -0.074 & $0.043 *$ & 0.005 \\
\hline Obs. & 447 & 1341 & 235 & 212 & 705 & 636 & 1788 & 447 & 940 & 848 \\
\hline \multicolumn{11}{|c|}{ High analyst coverage } \\
\hline Mean & $0.080 * * *$ & $0.060 * * *$ & $0.060 * *$ & $0.133 * * *$ & $0.061 * * *$ & $0.055^{* *}$ & 0.020 & -0.073 & -0.002 & $0.077 * *$ \\
\hline Obs. & 362 & 1086 & 261 & 101 & 783 & 303 & 1448 & 362 & 1044 & 404 \\
\hline \multicolumn{11}{|c|}{ Independent company } \\
\hline Mean & $0.103 * * *$ & $0.084 * * *$ & $0.083 * * *$ & $0.137 * * *$ & $0.071 * * *$ & $0.105^{* * *}$ & 0.019 & -0.055 & 0.011 & 0.032 \\
\hline Obs. & 700 & 2094 & 438 & 262 & 1314 & 780 & 2794 & 700 & 1752 & 1042 \\
\hline \multicolumn{11}{|c|}{ Controlling shareholder } \\
\hline Mean & $0.185 * * *$ & $0.215^{* * *}$ & $0.126^{* *}$ & $0.230 * * *$ & $0.058 * *$ & $0.333 * * *$ & -0.030 & -0.104 & $0.069^{*}$ & -0.103 \\
\hline Obs. & 118 & 363 & 51 & 67 & 156 & 207 & 481 & 118 & 207 & 274 \\
\hline
\end{tabular}

$*, * *$ and $* * *$ indicate statistical significance at the $10 \%, 5 \%$, and $1 \%$ levels, respectively 


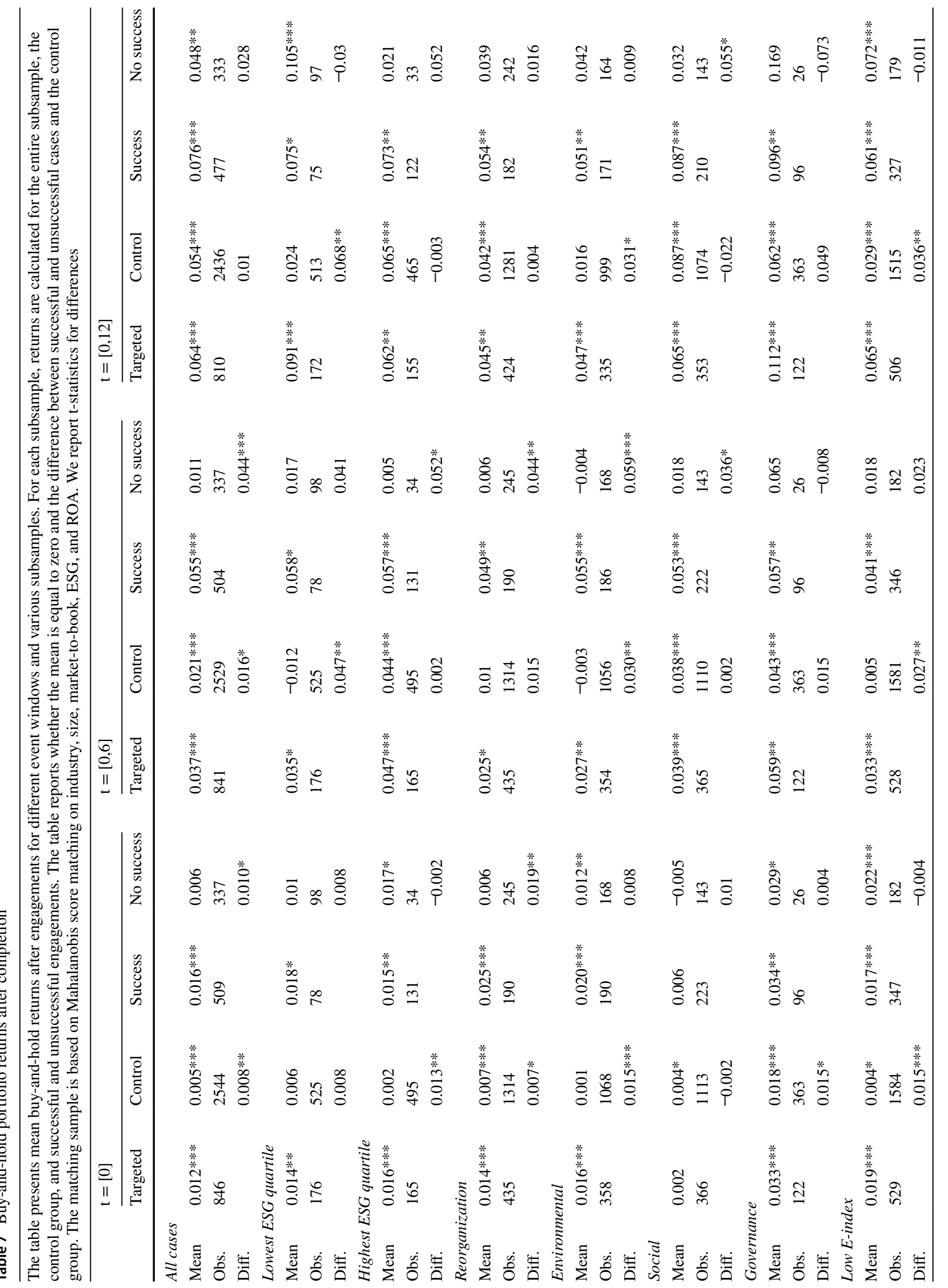




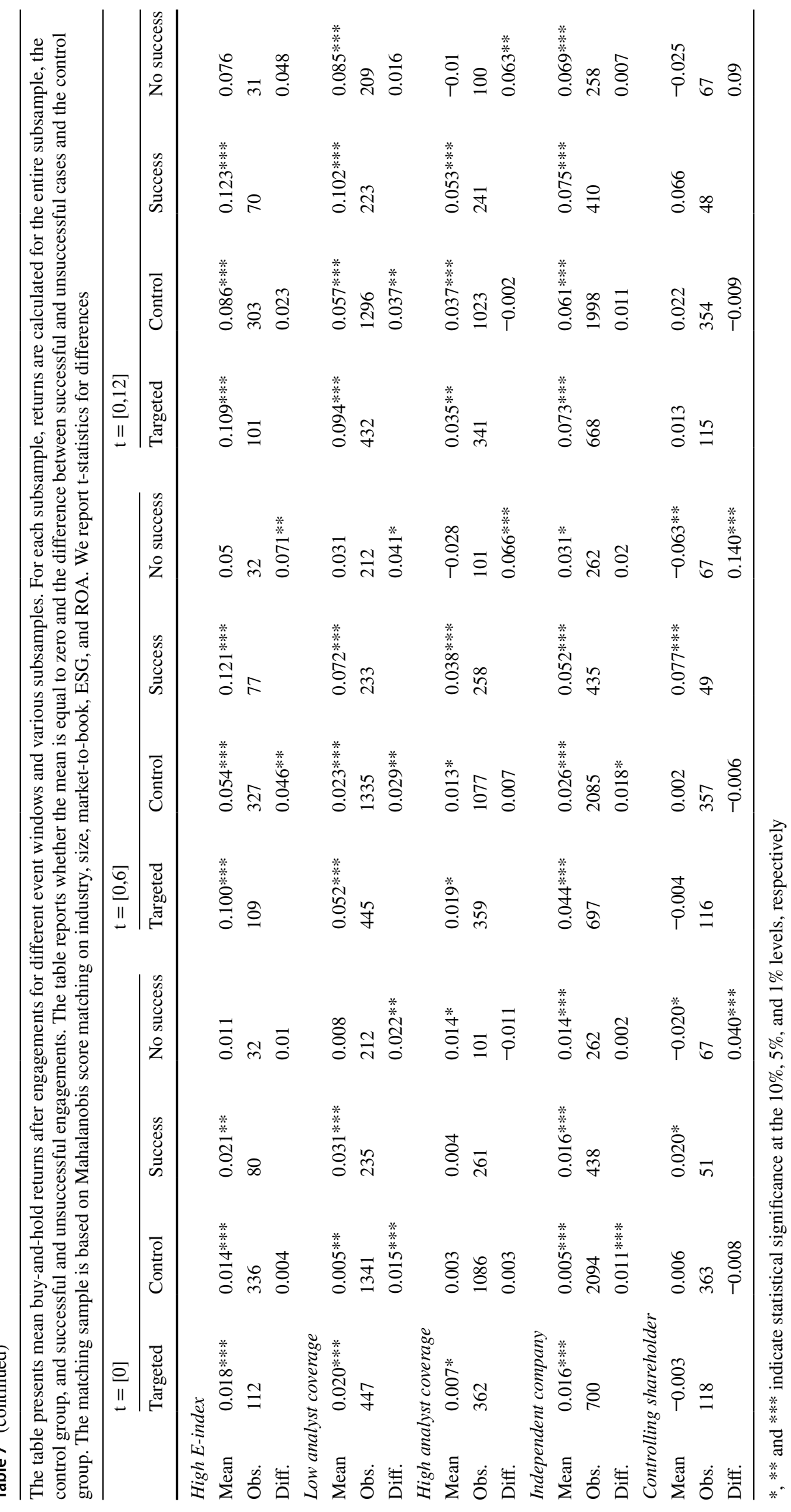




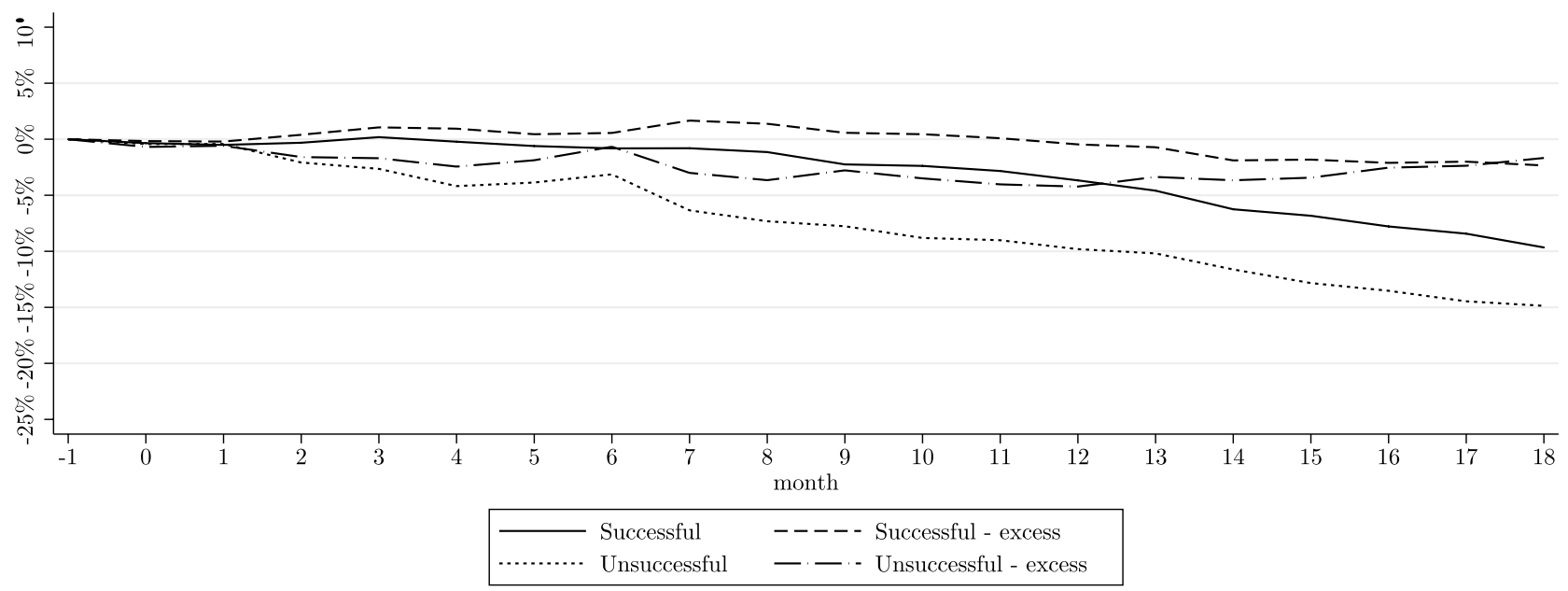

Fig. 3 Cumulative abnormal returns after completion. The figure shows cumulative abnormal returns for equally weighted portfolios of engaged companies and above a matched sample. The portfolios are formed at the completion of engagements. Returns are adjusted for Fama-French-Carhart global factors

which the activist demands a reorganization outperform the matched firms by $4.4 \%$ in the six months after the closure of the activist's case (but the difference between successfully or unsuccessfully closed files is not statistically significant).

Firms in the lowest (ex ante) ESG quartile outperform matched firms by $7.1 \%(7.5 \%)$ in the 6 months (1 year) after the engagement end. This implies that the targeting of low ESG firms prompts them to significantly outperform their non-engaged peers. Successfully engaged low-ESG firms outperform unsuccessfully engaged low-ESG firms. The successfully engaged low-ESG firms have an average ECAR of $8.4 \%$ over the 6-month period (outperforming the unsuccessfully engaged firms by $2.4 \%$ ) and of $11.3 \%$ over the year (outperforming the unsuccessfully engaged firms by 6.8\%). Similar patterns are not visible for engaged firms with an (ex ante) high ESG classification, as these firms do not obtain significant ECARs. Firms targeted for environmental or governance deficiencies exhibit significant and positive ECARs of $3 \%$ over a 6 -month period and $14.1 \%$ over a oneyear period, respectively. ${ }^{20}$

Figure 3 corroborates the findings in Table 8: the CARs for the successful engagements remain flat for about 6-7 months, after which they decline. The decrease in CARs for unsuccessful cases begins about one month after case completion. The gap in the CARs between successful and unsuccessful cases reaches a maximum after about 8-12 months.

\footnotetext{
18 The analysis of subsamples based on regions is not shown for reasons of conciseness but is available upon request.

19 As a robustness check, we also use Fama-French-Carhart factors, 17 Fama-French industry portfolios, as well as size and book-tomarket matched portfolios. We find that the results are qualitatively similar.
}

\footnotetext{
${ }^{20}$ Because the activist focuses mostly on the $\mathrm{E}$ and $\mathrm{S}$ factors and less on governance, the subsample of (un)successful cases is rather small, which may explain the reason why the unsuccessfully closed cases yield higher ECARs than the successful ones.
} 
Table 8 Excess cumulative abnormal returns at case closure

This table reports cumulative abnormal return statistics for various event windows and subsamples in excess of a matched sample. For each subsample, cumulative abnormal return statistics are reported for three event windows. For each event window and subsample combination, we test whether the mean cumulative abnormal return is 0 and the difference between successful and unsuccessful cases. The beginning of an event window is defined as the month when an engagement case is completed, the end of the window is either the month when the engagement is completed or 6 or 12 months following completion. The estimation period is 36 months prior to engagement. We use the Fama-French-Carhart model for the estimation of normal returns. Excess abnormal returns are calculated monthly subtracting the returns of an equally weighted portfolio of matched companies. The matching sample is based on Mahalanobis score matching on industry, size, market-to-book, ESG, and ROA. For each event window and subsample combination we test whether the mean cumulative abnormal return is 0 and the difference between successful and unsuccessful cases. We report t-statistics for differences.

\begin{tabular}{|c|c|c|c|c|c|c|c|c|c|}
\hline & \multicolumn{3}{|l|}{$\mathrm{t}=[0]$} & \multicolumn{3}{|l|}{$t=[0,6]$} & \multicolumn{3}{|l|}{$\mathrm{t}=[0,12]$} \\
\hline & All & Success & No success & All & Success & No success & All & Success & No success \\
\hline \multicolumn{10}{|l|}{ All cases } \\
\hline Mean & $0.005^{*}$ & 0.006 & 0.007 & $0.027 * * *$ & $0.022^{*}$ & $0.036 * *$ & 0.019 & 0.024 & 0.012 \\
\hline Obs. & 846 & 509 & 337 & 841 & 504 & 337 & 810 & 477 & 333 \\
\hline Difference & & 0.228 & & & -0.737 & & & 0.400 & \\
\hline \multicolumn{10}{|c|}{ Lowest ESG quartile } \\
\hline Mean & 0.006 & $0.025 * *$ & -0.001 & $0.071 * * *$ & $0.084 * *$ & $0.060^{*}$ & $0.075^{* *}$ & $0.113 * *$ & 0.045 \\
\hline Obs. & 176 & 78 & 98 & 176 & 78 & 98 & 172 & 75 & 97 \\
\hline Difference & & $2.488 * * *$ & & & 0.462 & & & 0.921 & \\
\hline \multicolumn{10}{|c|}{ Highest ESG quartile } \\
\hline Mean & 0.007 & 0.002 & 0.024 & 0.003 & 0.004 & 0.003 & -0.006 & -0.004 & -0.012 \\
\hline Obs. & 165 & 131 & 34 & 165 & 131 & 34 & 155 & 122 & 33 \\
\hline Difference & & -1.524 & & & 0.022 & & & 0.102 & \\
\hline \multicolumn{10}{|c|}{ Reorganization } \\
\hline Mean & 0.006 & 0.011 & 0.002 & $0.044 * * *$ & 0.035 & $0.051 * * *$ & 0.022 & 0.046 & 0.005 \\
\hline Obs. & 435 & 190 & 245 & 435 & 190 & 245 & 424 & 182 & 242 \\
\hline Difference & & 0.912 & & & -0.549 & & & 0.914 & \\
\hline \multicolumn{10}{|c|}{ Environmental } \\
\hline Mean & $0.009 * *$ & 0.005 & 0.014 & $0.030 * *$ & 0.008 & $0.055^{* *}$ & -0.004 & 0.001 & -0.010 \\
\hline Obs. & 358 & 190 & 168 & 354 & 186 & 168 & 335 & 171 & 164 \\
\hline Difference & & -0.887 & & & -1.711 & & & 0.237 & \\
\hline \multicolumn{10}{|l|}{ Social } \\
\hline Mean & 0 & 0.007 & -0.006 & 0.015 & 0.022 & 0.004 & -0.002 & 0.004 & -0.011 \\
\hline Obs. & 366 & 223 & 143 & 365 & 222 & 143 & 353 & 210 & 143 \\
\hline Difference & & $1.913 * *$ & & & 0.654 & & & 0.330 & \\
\hline \multicolumn{10}{|l|}{ Governance } \\
\hline Mean & 0.011 & 0.004 & 0.041 & 0.057 & 0.047 & 0.094 & $0.144 * * *$ & $0.109 * *$ & $0.272 * * *$ \\
\hline Obs. & 122 & 96 & 26 & 122 & 96 & 26 & 122 & 96 & 26 \\
\hline Difference & & -1.098 & & & -0.547 & & & -1.425 & \\
\hline \multicolumn{10}{|c|}{ Low E-index } \\
\hline Mean & $0.011^{*}$ & 0.006 & $0.023 * *$ & $0.045 * * *$ & $0.028^{*}$ & $0.077 * * *$ & $0.059 * * *$ & $0.041 *$ & $0.093 * * *$ \\
\hline Obs. & 529 & 347 & 182 & 528 & 346 & 182 & 506 & 327 & 179 \\
\hline Difference & & -1.329 & & & -1.831 & & & -1.294 & \\
\hline \multicolumn{10}{|c|}{ High E-index } \\
\hline Mean & 0.007 & 0.001 & $0.024 *$ & $0.033^{*}$ & 0.029 & 0.04 & 0.001 & -0.007 & 0.02 \\
\hline Obs. & 112 & 80 & 32 & 109 & 77 & 32 & 101 & 70 & 31 \\
\hline Difference & & -1.309 & & & -0.275 & & & -0.347 & \\
\hline \multicolumn{10}{|c|}{ Low analyst coverage } \\
\hline Mean & $0.014 * *$ & $0.024 * *$ & 0.004 & $0.032 * *$ & 0.024 & $0.041^{*}$ & 0.023 & 0.034 & 0.012 \\
\hline Obs. & 447 & 235 & 212 & 445 & 233 & 212 & 432 & 223 & 209 \\
\hline Difference & & $1.467^{*}$ & & & -0.583 & & & 0.491 & \\
\hline
\end{tabular}


Table 8 (continued)

This table reports cumulative abnormal return statistics for various event windows and subsamples in excess of a matched sample. For each subsample, cumulative abnormal return statistics are reported for three event windows. For each event window and subsample combination, we test whether the mean cumulative abnormal return is 0 and the difference between successful and unsuccessful cases. The beginning of an event window is defined as the month when an engagement case is completed, the end of the window is either the month when the engagement is completed or 6 or 12 months following completion. The estimation period is 36 months prior to engagement. We use the Fama-French-Carhart model for the estimation of normal returns. Excess abnormal returns are calculated monthly subtracting the returns of an equally weighted portfolio of matched companies. The matching sample is based on Mahalanobis score matching on industry, size, market-to-book, ESG, and ROA. For each event window and subsample combination we test whether the mean cumulative abnormal return is 0 and the difference between successful and unsuccessful cases. We report t-statistics for differences.

\begin{tabular}{|c|c|c|c|c|c|c|c|c|c|}
\hline & \multicolumn{3}{|c|}{$\mathrm{t}=[0]$} & \multicolumn{3}{|l|}{$t=[0,6]$} & \multicolumn{3}{|c|}{$\mathrm{t}=[0,12]$} \\
\hline & All & Success & No success & All & Success & No success & All & Success & No success \\
\hline \multicolumn{10}{|c|}{ High analyst coverage } \\
\hline Mean & 0.002 & -0.006 & $0.020^{*}$ & $0.027 * *$ & 0.018 & $0.048^{*}$ & 0.025 & 0.017 & 0.043 \\
\hline Obs. & 362 & 261 & 101 & 359 & 258 & 101 & 341 & 241 & 100 \\
\hline Difference & & -1.856 & & & -1.031 & & & -0.544 & \\
\hline \multicolumn{10}{|c|}{ Independent company } \\
\hline Mean & 0.007 & 0.004 & 0.011 & $0.024 * *$ & 0.014 & $0.041 * *$ & 0.019 & 0.014 & 0.026 \\
\hline Obs. & 700 & 438 & 262 & 697 & 435 & 262 & 668 & 410 & 258 \\
\hline Difference & & -0.632 & & & -1.213 & & & -0.357 & \\
\hline \multicolumn{10}{|c|}{ Controlling shareholder } \\
\hline Mean & 0.01 & $0.034 * *$ & -0.007 & 0.04 & $0.063 * *$ & 0.023 & 0.008 & 0.068 & -0.034 \\
\hline Obs. & 118 & 51 & 67 & 116 & 49 & 67 & 115 & 48 & 67 \\
\hline Difference & & $1.636^{*}$ & & & 0.761 & & & 1.26 & \\
\hline
\end{tabular}

$*, * *$ and $* * *$ indicate statistical significance at the $10 \%, 5 \%$, and $1 \%$ levels, respectively

For successfully engaged North American targets, CARs remain positive for about 9 months, then rapidly decline; for unsuccessfully engaged North American targets, CARs go down after 2 months, creating a big gap in CARs between successful and unsuccessful targets after about 8-9 months. For European targets, there is hardly a difference in CARs between (un)successful targets; CARs for both gradually decrease after about 9 months. ${ }^{21}$

Taken together, the results in Tables 7 and 8 imply that the activist can make a significant return by selling its stake in a successfully engaged target 6 to 12 months after closing the case.

\section{Conclusion}

Using a proprietary dataset of a large international, socially responsible activist fund, we analyze the reasons for, and the success of, corporate engagement involving mainly environmental and social issues. We match each engaged firm with three firms that were not engaged, that belong to the same industry, and that are most similar to the engaged firm in

\footnotetext{
21 The analysis on subsamples based on regions is not shown for rea-
} sons of conciseness but is available upon request. terms of size, market-to-book ratio, ROA, and ESG score in the year prior to the engagement.

The activist generally targets large firms with large market shares. Targeted firms are more likely to be in the highest ex ante ESG quartile. This is somewhat surprising, as one would expect the activist to concentrate on firms with poor ESG performance if ESG improvements are expected to generate value. Relative to the matched sample, the target firms have a higher stock market performance and a higher product market share and are more visible (have more analyst coverage). Firms that are engaged on corporate governance issues are somewhat smaller, have a more dispersed ownership structure, and have lower potential growth opportunities (Tobin's Q), but are otherwise profitable (both in terms of previous year buy-and-hold returns and accounting performance).

Next, we study whether the engagement is successfully completed. Success is defined as compliance with the activist's demands. One could question the relevance of this definition, considering that in some cases compliance may require little effort from the firm, while in others it may involve substantial changes-e.g., board or asset restructuring or overhauls of ESG-related operations. It is hence not surprising that when a "hard" engagement occurs, the 
likelihood of successful completion is lower than in cases that just require more ESG transparency or information provision.

We find that engagement success depends neither on joint targeting nor on the position of the main contact in the target firm (management or non-executive directors). More intensive contact between the activist and the target does yield success more frequently, though only for European targets. Companies that were targeted in the past and complied with the activist's requests are more likely to comply again if targeted. European firms under pressure-those with declines in sales and negative buy-and-hold returns-more frequently adopt the activist's suggestions. Our results also reveal that firms with a good ESG track record prior to the engagement (e.g., firms in the highest ESG performance quartile in North America and Europe) are more likely to comply. Firms that cared little about ESG issues ex ante seem to continue to do so, as they are reluctant to adopt suggestions by the CSR activist.

The real effects of engagement of the target firm are rather modest. Our differences-in-differences analyses reveal that, on average, accounting performance measures and their components do not significantly improve or change after engagement. The only exception is sales, which grows significantly after the engagement, both statistically and economically.

Interestingly, the mere engagement-independent of whether or not the case is successfully closed-triggers changes in the ESG profile of the target, which are picked up by the independent ESG evaluation providers. After the engagement, firms with poor ex ante ESG performance scores obtain higher scores, and firms with high ex ante ESG performance scores receive lower scores. If the activist correctly identifies companies with an ESG problem, then subsequent ESG ratings may reflect this new information, and the adjusted ESG scores then incorporate the potential ESG problem. In the case of firms with ex ante high scores, this drives the scores down. The engagement seems to reveal that previously low-rated companies are not "lost cases," and that best-performers might still have room for improvement. As the activist engages companies, the rating agency seems to realize that previous scores did not incorporate all of the activist's concerns, and that engaged companies still have key ESG points to improve on.

From the activist's perspective, activism seems to create, at best, modest financial returns during the engagement period, though we find no evidence that targets are negatively affected. Over the engagement period, targeted firms realize returns that are narrowly higher than those of the control firms over the same period. On average, the annualized BHRs of engaged firms are $2.6 \%$ higher than those of the control group, but the difference is not statistically significant. Engaged firms do perform significantly better in the engagement period when they are in the (ex ante) lowest ESG quartile, are subject to reorganization, or are engaged for environmental reasons.

On average, the buy-and-hold returns for completed engagements are positive and statistically significant in the month following the case closure (at $1.2 \%$, a significant 80 basis points higher than for the non-engaged control firms). These returns can be dissected into positive returns that stem from the successfully closed cases (generating BHRs of 1.6\%), and zero BHRs for unsuccessful engagements. Over longer time windows (e.g. 6 months), successful cases generate returns of $5.5 \%$, whereas unsuccessful ones have a return of zero. Successful reorganizations, which require the most compliance effort from the target, yield BHRs of $1.4 \%$ in the month the engagement is completed, increasing to $5.4 \%$ over a 1 -year time window, but these BHRs are not significantly different from those of the control sample. Still, successful reorganizations generate significantly higher BHRs than unsuccessful attempts, with differences of $1.9 \%$ over a 1 -month window and $4.4 \%$ over a six-month window.

When we partition the engagement files by ex ante ESG performance, we find significant differences: the largest BHRs are generated by targets in the ex ante lowest ESG quartile. Engaging these firms yields BHRs that are $4.7 \%$ and $6.8 \%$ higher than those of control firms over post-engagement time windows of 6 and 12 months, respectively. For targets in the ex ante highest ESG quartile, post-engagement BHRs are significantly higher (70 basis points) than those of the control firms in the month after the engagement. This finding is mainly due to successful engagements (which yield $2.5 \%$ in that month).

When we examine targets that are classified by ESG dimension, we find that environmental engagement leads to significant outperformance (BHRs are 3\% higher than those of the control firms over the year after the engagement). Over a 6-month time window after the engagement, successful environmental and social engagements outperform unsuccessful environmental and social engagements by $5.9 \%$ and $3.6 \%$, respectively.

When BHRs are calculated over the 18 months starting one month prior to the engagement, the greatest divergence is between successful and unsuccessful engagements, and occurs 6 to 12 months following the completion of the case.

An analysis of excess cumulative abnormal returnscontrolling for exposure to the global market, size, bookto-market, and momentum factors and measured relative to the CARs of matched peer firms - shows that that engaged firms slightly outperform non-engaged firms: the average ECARs are positive $(0.5 \%)$ and significantly different from zero in the month after the completion of the engagement, and augment to $2.7 \%$ over the 6 -month period after the engagement file is closed. Reorganization demands by the 
activist make a targeted firm outperform its non-targeted (but otherwise similar) peer company by $4.4 \%$ in the 6 months after the completion of the activist's case. Targeting firms in the lowest (ex ante) ESG quartile pays off, in that these firms outperform their matched peers by $7.1 \%$ $(7.5 \%)$ in the 6 months (1 year) after the activist ends the engagement. Furthermore, successfully engaged low-ESG firms outperform the unsuccessfully engaged low-ESG firms; the former have an average ECAR of $8.4 \%$ over the 6-month period (outperforming the unsuccessfully engaged firms by $2.4 \%$ ) and of $11.3 \%$ over the year (outperforming the unsuccessfully engaged firms by $6.8 \%$ ).

We conclude that our study provides direct evidence that ethical investing and strong performance can go handin-hand. The engagement from the activist investor seems most beneficial-both in terms of ESG performance and financial performance-for firms with ex-ante low ESG performance, suggesting that these ethical investors play an important role in helping firms understand how they can improve outcomes for all their stakeholders. Our results do not support the notion that the ESG efforts by activists and firms are merely for marketing or reputational purposes. On the other hand, our findings that the ESG ratings for targeted firms with ex-ante high ESG ratings tend to decline after targeting suggests that some of the activist investor's concerns have not been previously incorporated in the ratings and are then publicly disclosed due to the activism. This suggests both that ethical engagement affects ESG dislosure and that ESG ratings deserve close scrutiny.

\section{Appendix A: Engagement Case Examples}

\section{Environmental}

Amid a changing regulatory environment, the activist hired a third party analyst firm to evaluate the effects of new legislation on utility companies. The activist was specifically interested in the risks associated with the $\mathrm{CO} 2$ emissions of energy companies. After assessing the report, the activist reached out to company XXX on March 12, 2009. In a phone call, the activist requested information on two specific issues related to $\mathrm{CO} 2$ emissions. They were interested in the company's strategies to 1) reach statutory $\mathrm{CO} 2$ targets and 2) acquire and construct new power plants. Following up on the phone call, the activist paid a visit to XXX's headquarters on April 24, 2009, meeting an investor relations officer of the company. At this meeting, the activist elaborated on the requests in more detail, stressing that their ultimate goal was that the company publish a sustainability report in response to these requests. The company representative assured the activist that the company was aware of the changing regulatory environment and that they were already working on a sustainability report to appease investors. Following the publication of the report, the activist replied to the company in email on September 18, 2009, requesting more details on future power plants. This was followed by a further email on December 8. Finally, the company fulfilled all requests of the activist, publishing all information online. After the activist verified the published information, the case was closed as successful on February 25, 2010.

\section{Social}

The activist engaged financial institution YYY on March 10, 2006, to acquire more information on its human rights policies, after a January report by BankTrack indicated that YYY reported less information on the topic than its peers. Specifically, the activist was concerned about the ethical standards of the bank corresponding to investments in Russia and third world countries. The first meeting took place at the activist's offices with an investor relations officer of YYY. This meeting was followed by a conference call on April 6, 2006, during which a YYY executive assured the activist that the bank had "nothing to hide." Furthermore, the executive explained that they do take human rights issues into account for project financing and investments, although, as this was part of their internal scoring processes, they did not want to disclose details to maintain their competitive position. In response to the request for more transparency, the YYY executive promised that they would publish a sustainability report for 2006. Following the publication of the report, engagers had a last meeting on October 26, 2006, with the investor relations officer to go over the details of the report. As the report covered all concerns that the engager previously raised, the case was closed as "successful".

\section{Governance}

The activist engaged company ZZZ in 2007 concerning the size and composition of the supervisory board of the company. The activist was concerned that the board was not large enough to fully oversee the company's operations. A further concern was that the CEO of the company was also the chairman of the supervisory board. The activist voiced these concerns in collaboration with other investors at the AGM in mid-2007. ZZZ showed willingness to revise its governance practices. However, the CEO remained the chairman of the board. The activist revisited the case at the 2008 and 2009 AGMs to no avail. Since they could not reach their goal of improving ZZZ's corporate governance, they closed the case as "unsuccessful" on May 12, 2009. 


\section{Appendix B: Engagement Topics-Detailed}

\section{Environmental}

Climate Change: Carbon Disclosure Project, Climate Change

Ecosystem Services: Alternative Energy, Biodiversity, Eco-Efficiency; Emissions, Effluents and Waste; Nuclear Power, PVC and Phthalates, Tropical Hardwood, Water Environmental Management: Environmental Management, Environmental Policy \& Performance, Environmental Reporting, Environmental Supply Chain Standards

\section{Social}

Human Rights and Ethics: Animal Testing, Anti-Corruption, Customer Satisfaction, Ethics, Fur, Gambling, Human Rights, Military Production and Sales, Pornography and Adult Entertainment Services, Social Supply Chain Standards, Stakeholder Management \& Reporting, Sustainability Reporting
Labor Standards: Attraction \& Retention, Controversial Regimes, Forced and Compulsory Labor, Human Capital, Labor Standards, Privacy \& Freedom of Speech, Third World, Training \& Education, UN Global Compact

Public Health: Access to Medication, Alcohol, Genetic Engineering, Healthy Nutrition, Integration in Products, Intensive Farming \& Meat Sale, Product Safety, Tobacco

\section{Governance}

Corporate Governance: Board Practices, Governance Structure, Remuneration, Shareholder Rights, Supervisory Board

Management and Reporting: Accountability \& Transparency, Anti-Corruption, Corporate Strategy, Risk \& CrisisManagement, Stakeholder Management \& Reporting

\section{Appendix C}

See Table 9 
Table 9 Variable definitions

This table provides variable definitions. All variables based in $\$$ terms, if applicable.

\begin{tabular}{|c|c|c|}
\hline Variable & Definition & Source \\
\hline \multicolumn{3}{|l|}{ ESG scores } \\
\hline ESG sentiment & Annual average of ESG scores within a country. $(0-100)$ & Datastream - Asset 4 \\
\hline ESG score & $\begin{array}{l}\text { Equally weighted Asset } 4 \text { score: based on the Environmental, Social, Governance and Eco- } \\
\text { nomic pillars (0-100) }\end{array}$ & \\
\hline Environmental score & $\begin{array}{l}\text { Environmental pillar score: a company's impact on living and non-living natural systems, as } \\
\text { well as complete ecosystems }(0-100)\end{array}$ & \\
\hline Social score & $\begin{array}{l}\text { Social pillar score: a company's ability to generate trust and loyalty with its workforce, cus- } \\
\text { tomers and society }(0-100)\end{array}$ & \\
\hline Governance score & $\begin{array}{l}\text { Governance pillar score: a company's systems and practices that ensure that its executives and } \\
\text { board act in the interest of (long-term) shareholders }(0-100)\end{array}$ & \\
\hline Economic score & $\begin{array}{l}\text { Economic pillar score: a company's capacity to generate sustainable growth and returns } \\
\text { through the efficient use of its assets and resources }(0-100)\end{array}$ & \\
\hline Entrenchment index & $\begin{array}{l}\text { Index of entrenchment measures (E-index): poison pill, golden parachute, staggered board, } \\
\text { bylaws and lock-ins }(0-1)\end{array}$ & \\
\hline \multicolumn{3}{|l|}{ Risk and performance } \\
\hline BHR & Buy-and-hold stock return over 12 months & Datastream \\
\hline Volatility & Stock return volatility & \\
\hline Amihud ILLIQ & Amihud illiquidity measure multiplied by $\$ 1$ million & \\
\hline Asset turnover & (Total sales)/(Total assets) & \\
\hline Profit margin & (Net income)/(Total sales) & \\
\hline ROA & (Net income)/(Total assets) & \\
\hline ROE & (Net income)/(Book value of equity) & \\
\hline Sales growth & Year-over-year sales growth & \\
\hline Sales market share & Percentage of total industry sales & \\
\hline Market-to-book & (Market value of equity)/(Book value of equity) & \\
\hline Tobin's Q & (Market value of equity + Total book liabilities)/(Book value of equity + Total book liabilities $)$ & \\
\hline \multicolumn{3}{|l|}{ Cash and expenses } \\
\hline Cash holding & (Total cash)/(Total assets) & Datastream \\
\hline CapEX & (Capital Expenditures)/(Total assets) & \\
\hline Operating expenses & (Operating expenses)/(Sales) & \\
\hline SGA & (Selling, General and Administrative expenses)/(Total assets) & \\
\hline \multicolumn{3}{|c|}{ Size and capital structure } \\
\hline Log total assets & Natural log of total assets & Datastream \\
\hline Log sales & Natural log of total sales & \\
\hline Log market equity & Natural log of total market capitalization & \\
\hline Book leverage & (Total book liabilities)/(Total book liabilities + Book value of equity) & \\
\hline Tangibility ratio & (Plant, property and equipment)/(Total assets) & \\
\hline Equity issuance & (Annual change in equity issue and redemption)/(Lagged total assets) & \\
\hline Debt issuance & (Annual change in long and current debt)/(Lagged total assets) & \\
\hline \multicolumn{3}{|l|}{ Other } \\
\hline Dividend yield & (Total dividends paid)/(Market value of equity + Market value of preferred shares) & Datastream \\
\hline Dividend payout & (Total dividends paid)/(Net income) & \\
\hline Company age & Years since incorporation or IPO date & \\
\hline Analysts & Mean number of analysts issuing earnings (EPS) forecasts annually & $\mathrm{I} / \mathrm{B} / \mathrm{E} / \mathrm{S}$ \\
\hline Common law & $\begin{array}{l}\text { Indicator if a company is headquartered in a common law country, following the classification } \\
\text { of Liang and Renneboog (2017). } 1 \text { for common law, } 0 \text { otherwise. }\end{array}$ & Datastream \\
\hline \multicolumn{3}{|l|}{ Ownership } \\
\hline Holding of engager & Portfolio holdings of engager (total) & Morningstar \\
\hline Toehold & Indicator variable; 1 if the engager increases its holdings prior to targeting & \\
\hline Toehold increase & Indicator variable; 1 if the engager increases its holdings over the course of targeting & \\
\hline
\end{tabular}


Table 9 (continued)

This table provides variable definitions. All variables based in $\$$ terms, if applicable.

\begin{tabular}{|c|c|c|}
\hline Variable & Definition & Source \\
\hline Average ownership & Mean of ownership stakes & \multirow[t]{7}{*}{ Orbis } \\
\hline Number of blockholders & Number of owners with a $+5 \%$ stake & \\
\hline Long-term investors & Holdings by pension and mutual funds & \\
\hline Hedge funds and PE & Holdings by edge funds, venture capitalists and private equity firms & \\
\hline Individuals and family & Holdings by individuals and families & \\
\hline Independent company & \multirow[t]{2}{*}{ Indicator if a company has no majority shareholder with a stake larger than $25 \%$} & \\
\hline Miscellaneous & & \\
\hline Contact number & Number of contacts with the target company & Activist \\
\hline Contact type & The dominant channel of communication & \\
\hline Contacted executives & Role of contact person at target company; 1 for executive officers, 0 otherwise & \\
\hline Geographic FE & Fixed effects for Asia, Europe, North America and Other regions & \\
\hline Industry FE & Fixed effects for 17 Fama-French industries & \\
\hline Joint targeting & Targeting in collaboration with other activists; 1 if jointly targeted, 0 otherwise & \\
\hline Length of sequence & Time span of targeting in days & \\
\hline Previous engagements & Number of previous cases with the same company & \\
\hline Success & The originally defined goal is achieved; 1 for success, 0 otherwise & \\
\hline Success streak & Number of previous successful cases with the same company & \\
\hline Receptiveness & 1 if the target firm is initially willing to collaborate with the activist; 0 otherwise & \\
\hline Reorganization & $\begin{array}{l}1 \text { for material request aimed at changing the company's operations; } 0 \text { for an engagement aimed } \\
\text { at enhancing transparency }\end{array}$ & \\
\hline
\end{tabular}

\section{Appendix D: Analysis by Geography and Legal Origin}

See Figs. 4, 5 and Tables 10, 11, 12.

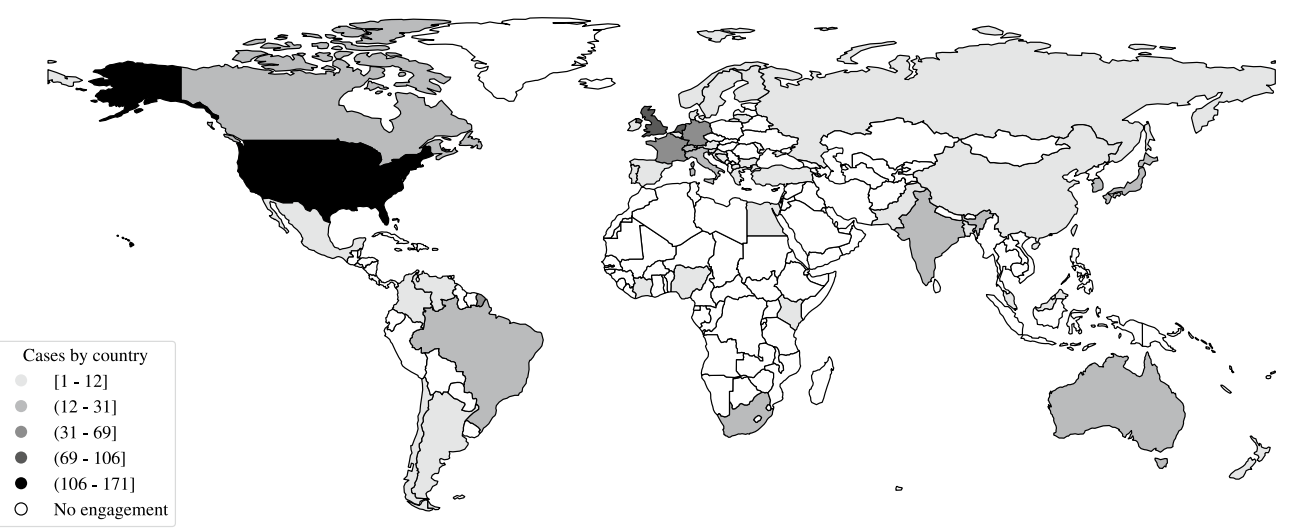

Fig. 4 Global heat map by number of engagements. The figure depicts the geographical concentration of engagement cases across the globe 


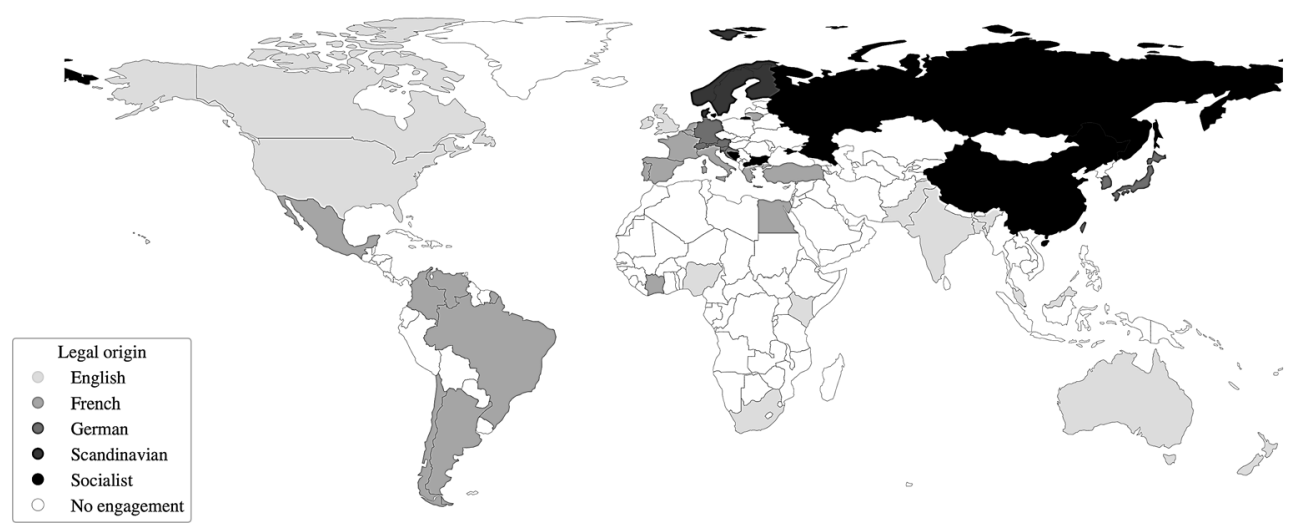

Fig. 5 Country legal origin. The graph indicates the legal origin of countries where engaged companies are headquartered. We follow Liang and Renneboog (2017) in classifying countries by their legal origin

Table 10 Cases by domicile and legal origin

This table reports the country distribution of engagement cases as well as the legal origin of the country. We follow Liang and Renneboog (2017) in classifying countries by their legal origin.

\begin{tabular}{llll}
\hline ISO code & Country name & Cases & Legal origin \\
\hline ARG & Argentina & 5 & French \\
AUS & Australia & 15 & English \\
AUT & Austria & 3 & German \\
BEL & Belgium & 5 & French \\
BGD & Bangladesh & 1 & English \\
BGR & Bulgaria & 2 & Socialist \\
BIH & Bosnia and Herzegovina & 1 & Socialist \\
BRA & Brazil & 17 & French \\
CAN & Canada & 31 & English \\
CHE & Switzerland & 28 & German \\
CHL & Chile & 2 & French \\
CHN & China & 7 & Socialist \\
CIV & Côte d'Ivoire & 1 & French \\
COL & Colombia & 1 & French \\
DEU & Germany & 66 & German \\
DNK & Denmark & 6 & Scandinavian \\
EGY & Egypt & 1 & French \\
ESP & Spain & 12 & French \\
FIN & Finland & 8 & Scandinavian \\
FRA & France & 69 & French \\
GBR & United Kingdom & 90 & English \\
GRC & Greece & 2 & French \\
HKG & Hong Kong & 12 & English \\
HRV & Croatia & 2 & German \\
IND & India & 2 & English \\
IRL & Ireland & & English \\
\hline & &
\end{tabular}

Table 10 (continued)

This table reports the country distribution of engagement cases as well as the legal origin of the country. We follow Liang and Renneboog (2017) in classifying countries by their legal origin.

\begin{tabular}{|c|c|c|c|}
\hline ISO code & Country name & Cases & Legal origin \\
\hline$\overline{\text { ISR }}$ & Israel & 1 & English \\
\hline ITA & Italy & 23 & French \\
\hline JPN & Japan & 22 & German \\
\hline KEN & Kenya & 1 & English \\
\hline KOR & South Korea & 26 & German \\
\hline LTU & Lithuania & 3 & French \\
\hline LUX & Luxembourg & 2 & French \\
\hline MEX & Mexico & 6 & French \\
\hline MKD & Macedonia & 1 & Socialist \\
\hline MYS & Malaysia & 1 & English \\
\hline NGA & Nigeria & 2 & English \\
\hline NLD & Netherlands & 106 & French \\
\hline NOR & Norway & 7 & Scandinavian \\
\hline NZL & New Zealand & 1 & English \\
\hline PAK & Pakistan & 9 & English \\
\hline PRT & Portugal & 1 & French \\
\hline RUS & Russia & 2 & Socialist \\
\hline SGP & Singapore & 18 & English \\
\hline SVN & Slovenia & 1 & German \\
\hline SWE & Sweden & 10 & Scandinavian \\
\hline TUR & Turkey & 2 & French \\
\hline TWN & Taiwan & 2 & German \\
\hline USA & United States of America & 171 & English \\
\hline VEN & Venezuela & 1 & French \\
\hline ZAF & South Africa & 19 & English \\
\hline
\end{tabular}


Table 11 Analysis of targeting by regions

This table reports the marginal effects obtained from probit regressions on the probability of targeting relative to a matched sample. The first two columns report regression results for the whole sample of engagements (1-2), while the second, third, and fourth sets of columns refer to North American (3-4), European (5-6), and Other domiciled (7-8) companies, respectively.The dependent variable equals 1 if the company is targeted and 0 otherwise. Marginal effects are evaluated at the mean of the respective independent variable. Standard errors are clustered at the firm level. The matching sample is determined by Mahalanobis score matching on industry, size, market-to-book, ESG, and ROA. Variable definitions are provided in the Appendix

\begin{tabular}{|c|c|c|c|c|c|c|c|c|}
\hline & \multicolumn{2}{|c|}{ Full sample } & \multicolumn{2}{|c|}{ North America } & \multicolumn{2}{|l|}{ Europe } & \multicolumn{2}{|l|}{ Other } \\
\hline & (1) & (2) & (3) & (4) & $(5)$ & (6) & (7) & (8) \\
\hline Log total assets & $-0.031 * *$ & 0.025 & 0.029 & 0.041 & $-0.067 * * *$ & -0.002 & 0.030 & $0.081 * *$ \\
\hline Tobin's Q & 0.000 & 0.002 & -0.004 & 0.011 & -0.008 & -0.001 & 0.027 & 0.021 \\
\hline Sales growth & -0.056 & -0.072 & $-0.183^{* * *}$ & $-0.212 * *$ & 0.019 & -0.011 & -0.048 & -0.148 \\
\hline BHR over 12 months & $0.077 * * *$ & $0.096 * * *$ & -0.046 & -0.018 & $0.082 * * *$ & $0.087 * * *$ & $0.073 * *$ & 0.032 \\
\hline ROA & 0.253 & 0.097 & $0.641^{*}$ & 0.522 & -0.065 & -0.225 & 0.209 & -0.153 \\
\hline Sales market share & $3.899 * * *$ & $2.752 * * *$ & $3.304 * * *$ & $3.646^{* *}$ & $3.764 * * *$ & $2.209 * * *$ & 1.628 & 0.083 \\
\hline Cash holding & -0.097 & 0.066 & 0.138 & 0.217 & -0.109 & 0.121 & -0.212 & -0.474 \\
\hline Book leverage & 0.078 & 0.038 & 0.016 & 0.136 & 0.036 & -0.049 & -0.037 & -0.115 \\
\hline Dividend yield & 0.547 & 0.953 & -0.056 & 0.975 & $0.990^{*}$ & 0.715 & 0.495 & $1.917 * *$ \\
\hline CapEX & 0.103 & 0.271 & 0.059 & -0.027 & -0.444 & 0.037 & $0.980 * *$ & 0.280 \\
\hline Amihud ILLIQ & -0.006 & $-0.544 * *$ & -0.003 & $-214.903 * * *$ & 0.002 & $-0.255^{* *}$ & -0.005 & -0.414 \\
\hline Analysts & $0.012 * * *$ & $0.010 * * *$ & -0.001 & -0.000 & $0.017 * * *$ & $0.010 * * *$ & $-0.008^{* *}$ & -0.002 \\
\hline SGA & 0.044 & 0.165 & 0.128 & 0.180 & 0.053 & 0.122 & -0.051 & 0.348 \\
\hline Common law & $-0.071 * *$ & -0.028 & $0.483 * * *$ & 0.000 & $-0.188 * * *$ & $-0.098 * * *$ & -0.015 & $0.100^{*}$ \\
\hline Previous engments & $-0.023 * *$ & $-0.030 * * *$ & -0.036 & -0.043 & $-0.022 * *$ & $-0.029 * * *$ & -0.020 & 0.019 \\
\hline Holding of engager & & 3.027 & & $47.694 * *$ & & $2.662 *$ & & $27.015^{* *}$ \\
\hline Independent company & & -0.005 & & -0.056 & & 0.014 & & 0.105 \\
\hline ESG sentiment & & $0.008 * * *$ & & 0.027 & & -0.057 & & $-0.339 * *$ \\
\hline Entrenchment index & & -0.025 & & -0.008 & & $0.010 * * *$ & & $-0.010 * * *$ \\
\hline ESG score & & $-0.160 * * *$ & & 0.030 & & $-0.111 *$ & & -0.022 \\
\hline Year dummy & yes & yes & yes & yes & yes & yes & yes & yes \\
\hline Industry dummy & yes & yes & yes & yes & yes & yes & yes & yes \\
\hline Geographic dummy & yes & yes & no & no & no & no & no & no \\
\hline Pseudo $\mathrm{R}^{2}$ & 0.12 & 0.23 & 0.22 & 0.28 & 0.33 & 0.46 & 0.07 & 0.35 \\
\hline $\mathrm{N}$ & 2,567 & 2,028 & 698 & 438 & 1,345 & 1,174 & 524 & 254 \\
\hline
\end{tabular}

$*, * *$ and $* * *$ indicate statistical significance at the $10 \%, 5 \%$, and $1 \%$ levels, respectively 
Table 12 Analysis of success by regions

This table reports the marginal effects obtained from linear probability regressions on the probability of success. The dependent variable equals 1 if the engagement is successful and 0 otherwise. The first two columns report regression results for the whole sample of engagements (1-2), while the second, third, and fourth sets of columns refer to North American (3-4), European (5-6) and Other domiciled (7-8) companies, respectively. Standard errors are clustered at the firm level. The dummy "Reorganization" takes the value 1 for reorganization cases and 0 otherwise. The dummy variable "Joint targeting" equals one for cases where the engager contacts the company with other activists. The variable "Contacted executives" is 1 if executive management is contacted and 0 otherwise. "Number of activities" and "Success streak" refer to the number of contacts per case and the number of previous successful cases with the company. Other variable definitions are provided in the Appendix

\begin{tabular}{|c|c|c|c|c|c|c|c|c|}
\hline & \multicolumn{2}{|l|}{ Full sample } & \multicolumn{2}{|c|}{ North America } & \multicolumn{2}{|l|}{ Europe } & \multicolumn{2}{|l|}{ Other } \\
\hline & (1) & (2) & (3) & (4) & (5) & (6) & (7) & (8) \\
\hline Reorganization & $-0.163^{* * *}$ & $-0.144 * *$ & $-0.274^{*}$ & -0.255 & $-0.143 * * *$ & $-0.120 * *$ & 0.079 & 0.053 \\
\hline Joint targeting & $0.094 *$ & 0.039 & $0.258 * *$ & $0.232 *$ & 0.001 & -0.043 & 0.165 & -0.251 \\
\hline Contacted executives & $-0.111 * *$ & -0.090 & -0.160 & -0.236 & 0.017 & 0.045 & $-0.374 * *$ & 0.029 \\
\hline Number of contacts & 0.008 & 0.006 & 0.003 & -0.003 & 0.014 & 0.011 & 0.037 & 0.051 \\
\hline Success streak & 0.010 & 0.010 & 0.046 & 0.008 & 0.015 & 0.008 & 0.102 & 0.181 \\
\hline Log total assets & 0.020 & -0.036 & -0.023 & $-0.094^{*}$ & $0.052 *$ & 0.054 & 0.049 & 0.013 \\
\hline Tobin's Q & -0.030 & -0.023 & 0.018 & 0.005 & -0.037 & -0.021 & -0.045 & $-0.253^{*}$ \\
\hline Sales growth & $-0.357 * * *$ & $-0.333 * * *$ & -0.083 & -0.152 & $-0.415^{* * *}$ & $-0.447 * * *$ & -0.289 & 0.211 \\
\hline BHR over 12 months & 0.036 & -0.019 & $0.202 * *$ & $0.184 *$ & -0.081 & $-0.200 * *$ & 0.079 & 0.457 \\
\hline ROA & -0.342 & -0.596 & -0.820 & $-1.555^{*}$ & 0.154 & 0.121 & -0.116 & -4.706 \\
\hline Sales market share & 1.357 & $1.903 * *$ & 1.829 & 1.447 & -0.002 & -0.630 & 0.046 & -6.106 \\
\hline Cash holding & -0.392 & $-0.804 * *$ & $-1.026^{* *}$ & $-1.082 * *$ & -0.289 & -0.673 & 0.449 & 1.259 \\
\hline Book leverage & 0.040 & -0.103 & $-0.371^{*}$ & $-0.456^{* *}$ & 0.199 & 0.123 & 0.235 & -0.791 \\
\hline Dividend yield & 0.230 & 0.490 & 1.048 & $4.164 * *$ & -1.661 & -2.226 & 1.770 & 6.248 \\
\hline CapEX & -0.258 & 0.515 & $1.398 *$ & $2.045^{* *}$ & $-1.177 *$ & -0.597 & -0.276 & 1.091 \\
\hline Amihud ILLIQ & -0.011 & 0.299 & $0.099 * * *$ & $-277.833 * * *$ & 0.072 & 0.226 & -0.053 & 19.770 \\
\hline Analysts & 0.001 & -0.001 & -0.002 & -0.002 & 0.001 & -0.003 & 0.000 & -0.010 \\
\hline SGA & $0.725^{* * *}$ & $0.597 * * *$ & 0.442 & 0.342 & $0.619 * * *$ & $0.663 * * *$ & 0.476 & 1.033 \\
\hline Common law & -0.008 & -0.031 & - & - & - & - & - & - \\
\hline Toehold & & 0.008 & & 0.012 & & -0.002 & & 0.065 \\
\hline Toehold increase & & -0.036 & & -0.013 & & 0.039 & & -0.032 \\
\hline Independent company & & 0.111 & & 0.056 & & 0.011 & & 0.082 \\
\hline Entrenchment index & & 0.033 & & 0.028 & & $0.239 *$ & & 1.086 \\
\hline ESG sentiment & & 0.000 & & $-0.057 * * *$ & & 0.002 & & -0.013 \\
\hline ESG score & & $0.366^{* *}$ & & $0.474 *$ & & 0.108 & & 0.972 \\
\hline Year dummy & yes & yes & yes & yes & yes & yes & yes & yes \\
\hline Industry dummy & yes & yes & no & no & no & no & no & no \\
\hline Geographic dummy & yes & yes & no & no & no & no & no & no \\
\hline Adjusted $\mathrm{R}^{2}$ & 0.25 & 0.24 & 0.18 & 0.28 & 0.29 & 0.26 & 0.20 & 0.69 \\
\hline $\mathrm{N}$ & 616 & 471 & 186 & 162 & 317 & 268 & 113 & 41 \\
\hline
\end{tabular}

$*, * *$ and $* * *$ indicate statistical significance at the $10 \%, 5 \%$, and $1 \%$ levels, respectively

Acknowledgements We would like to thank the data provider for providing us with detailed, proprietary information on their shareholder activism procedures. We would like to thank the editor, as well as three anonymous referees for their suggestions on improving the paper. We are grateful for comments from Fabio Braggion, Peter Cziraki, Frank de Jong, Bart Dierynck, Elroy Dimson, Joost Driessen, Alex Edmans, Caroline Flammer, Julian Franks, William Goetzmann, Marc Goergen, Muris Hadzic, Camille Hebert, Hao Liang, Alberto Manconi, Ernst Maug, Anjana Rajamani, Zorka Simon, Oliver Spalt, Michael Ungehauer, Servaes van der Meulen, Cara Vansteenkiste, Chendi Zhang, Yang Zhao, and seminar participants at the HAS Summer Workshop in Economics, ICGN, the 2nd Conference on CSR, the Economy, and Financial Markets, University of Mannheim, Cardiff Business School, Ghent University, Tilburg University, and University Paris-Dauphine. An earlier version of this paper was titled "Activism on Corporate Social Responsibility." Disclaimer: The views, information, or opinions expressed in this paper are solely those of the individuals involved and do not necessarily represent those of Prime Capital AG and its employees. 


\section{Declarations}

Conflict of interest The authors declare that they have no conflict of interest.

Open Access This article is licensed under a Creative Commons Attribution 4.0 International License, which permits use, sharing, adaptation, distribution and reproduction in any medium or format, as long as you give appropriate credit to the original author(s) and the source, provide a link to the Creative Commons licence, and indicate if changes were made. The images or other third party material in this article are included in the article's Creative Commons licence, unless indicated otherwise in a credit line to the material. If material is not included in the article's Creative Commons licence and your intended use is not permitted by statutory regulation or exceeds the permitted use, you will need to obtain permission directly from the copyright holder. To view a copy of this licence, visit http://creativecommons.org/licenses/by/4.0/.

\section{References}

Albuquerque, R., Koskinen, Y., \& Zhang, C. (2019). Corporate social responsibility and firm risk: Theory and evidence. Management Science, 65(10), 4451-4469.

Attig, N., Boubakri, N., El Ghoul, S., \& Guedhami, O. (2016). Firm internationalization and corporate social responsibility. Journal of Business Ethics, 134(2), 171-197.

Barko, T., \& Renneboog, L. (2016). Mutual funds: Management styles, social responsibility, performance, and efficiency (pp. 268-290). New York: Oxford University Press.

Baron, D. P. (2008). Managerial contracting and corporate social responsibility. Journal of Public Economics, 92(1-2), 268-288.

Bebchuk, L. A., Brav, A., \& Jiang, W. (2015). The long-term effects of hedge fund activism. Columbia Law Review, 115(5), 1085-1155.

Bebchuk, L. A., Cohen, A., \& Ferrell, A. (2009). What matters in corporate governance? The Review of Financial Studies, 22(2), 783-827.

Becht, M., Franks, J., Grant, J., \& Wagner, H. (2017). Returns to Hedge fund activism: An international study. The Review of Financial Studies, 30(9), 2933-2971.

Becht, M., Franks, J., Mayer, C., \& Rossi, S. (2009). Returns to shareholder activism: Evidence from a clinical study of the Hermes UK Focus Fund. The Review of Financial Studies, 22(8), 3093-3129.

Bénabou, R., \& Tirole, J. (2006). Incentives and prosocial behavior. American Economic Review, 96(5), 1652-1678.

Benmelech, E., \& Dlugosz, J. (2009). The credit rating crisis. NBER Macro Annual, 24(1), 161-207.

Bollen, N. (2007). Mutual fund attributes and investor behavior. Journal of Financial and Quantitative Analysis, 42(3), 683-708.

Boubakri, N., El Ghoul, S., Guedhami, O., \& Megginson, W. L. (2018). The market value of government ownership. Journal of Corporate Finance, 50, 44-65.

Boubakri, N., El Ghoul, S., Wang, H., Guedhami, O., \& Kwok, C. C. (2016). Cross-listing and corporate social responsibility. Journal of Corporate Finance, 41, 123-138.

Brav, A., Jiang, W., Partnoy, F., \& Thomas, R. (2008). Hedge fund activism, corporate governance, and firm performance. The Journal of Finance, 63(4), 1729-1775.

Capelle-Blancard, G., \& Monjon, S. (2014). The performance of socially responsible funds: Does the screening process matter? European Financial Management, 20(3), 494-520.

Cremers, M., Giambona, E., Sepe, S. M., \& Wang, Y. (2020). Hedge fund activism and long-term firm value. Working paper.
Cremers, M., \& Petajisto, A. (2009). How active is your fund manager? A new measure that predicts performance. The Review of Financial Studies, 22(9), 3329-3365.

Dembinski, P. H., Bonvin, J.-M., Dommen, E., \& Monnet, F.-M. (2003). The ethical foundations of responsible investment. Journal of Business Ethics, 48(2), 203-213.

Di Giuli, A., \& Kostovetsky, L. (2014). Are red or blue companies more likely to go green? Politics and corporate social responsibility. Journal of Financial Economics, 111(1), 158-180.

Dimson, E., Karakaş, O., \& Li, X. (2015). Active ownership. The Review of Financial Studies, 28(12), 3225-3268.

Doidge, C., Dyck, A., Mahmudi, H., \& Virani, A. (2019). Can institutional investors improve corporate governance through collective action. Review of Finance, 23(5), 893-933.

Dupire, M., \& Mzali, B. (2018). CSR strategies in response to competitive pressures. Journal of Business Ethics, 148(3), 603-623.

Duuren, E., Plantinga, A., \& Scholtens, B. (2016). ESG integration and the investment management process: Fundamental investing reinvented. Journal of Business Ethics, 138(3), 525-533.

Dyck, A., Lins, K. V., Roth, L., \& Wagner, H. (2019). Do institutional investors drive corporate social responsibility? International evidence. Journal of Financial Economics, 131(3), 693-714.

Edmans, A. (2011). Does the stock market fully value intangibles? Employee satisfaction and equity prices. Journal of Financial Economics, 101(3), 621-640.

Edmans, A. (2012). The link between job satisfaction and firm value, with implications for corporate social responsibility. The Academy of Management Perspectives, 26(4), 1-19.

Edmans, A., \& Holderness, C. G. (2017). Blockholders: A survey of theory and evidence. North Holland: Elsevier.

El Ghoul, S., Guedhami, O., Kwok, C. C. Y., \& Mishra, D. R. (2011). Does corporate social responsibility affect the cost of capital? Journal of Banking \& Finance, 35(9), 2388-2406.

English, P. C., Smythe, T. I., \& McNeil, C. R. (2004). The CalPERS effect revisited. Journal of Corporate Finance, 10(1), 157-174.

Eurosif, . (2018). European SRI Study 2018. Eurosif: Report.

Ferrell, A., Liang, H., \& Renneboog, L. (2016). Socially responsible firms. Journal of Financial Economics, 122(3), 585-606.

Flammer, C. (2015). Does corporate social responsibility lead to superior financial performance? A regression discontinuity approach. Management Science, 61(11), 2549-2568.

Friedman, M. (1970). The social responsibility of business is to increase its profits. The New York Times Magazine.

Gaspar, J.-M., Massa, M., Matos, P., Patgiri, R., \& Rehman, Z. (2013). Payout policy choices and shareholder investment horizons. Review of Finance, 17(1), 261-320.

Gibson, R., P. Krueger, and S. F. Mitali (2020). The Sustainability Footprint of Institutional Investors: ESG Driven Price Pressure and Performance. Working paper 17-05, Swiss Finance Institute.

Gil-Bazo, J., Ruiz-Verdu, P., \& Santos, A. A. P. (2010). The performance of socially responsible mutual funds: The role of fees and management companies. Journal of Business Ethics, 94(2), 243-263

Gillan, S. L., \& Starks, L. T. (2007). The evolution of shareholder activism in the United States. Journal of Applied Corporate Finance, 19(1), 55-73.

Global Sustainable Investment Alliance (2013). Global Sustainable Investment Review 2012. Global Sustainable Investment Alliance.

Global Sustainable Investment Alliance (2019). Global Sustainable Investment Review 2018. Global Sustainable Investment Alliance.

Greenwood, R., \& Schor, M. (2009). Investor activism and takeovers. Journal of Financial Economics, 92(3), 362-375.

Hoepner, A., I. Oikonomou, Z. Sautner, L. T. Starks, and X. Zhou (2020). ESG Stakeholder Engagement and Downside Risk. ECGI working paper $671 / 2020$. 
Hong, H., J. D. Kubik, I. Liskovich, and J. A. Scheinkman (2015). Crime, Punishment and the Halo Effect of Corporate Social Responsibility. Working paper 21215.

Hong, H., J. D. Kubik, and J. A. Scheinkman (2012). Financial Constraints on Corporate Goodness. Working paper.

Klein, A., \& Zur, E. (2009). Entrepreneurial shareholder activism: Hedge funds and other private investors. The Journal of Finance, 64(1), 187-229.

Klein, A., \& Zur, E. (2011). The impact of hedge fund activism on the target firms existing bondholders. The Review of Financial Studies, 24(5), 1735-1771.

Krueger, P. (2013). Corporate goodness and shareholder wealth. Journal of Financial Economics, 115(2), 304-329.

Lee, G., \& Xiao, X. (2020). Voluntary engagement in environmental projects: Evidence from environmental violators. Journal of Business Ethics, 164(2), 325-348.

Leiva, R., Ferrero, I., \& Calderón, R. (2016). Corporate reputation in the business ethics field: Its relation with corporate identity, corporate image, and corporate social responsibility. Corporate Reputation Review, 19(4), 299-315.

Leuven, E. and B. Sianesi (2003). PSMATCH2: Stata Module to Perform Full Mahalanobis and Propensity Score Matching, Common Support Graphing, and Covariate Imbalance Testing. Statistical Software Components.

Lewis, A., \& Mackenzie, C. (2000). Support for investor activism among U.K. ethical investors. Journal of Business Ethics, 24(3), 215-222.

Liang, H., \& Renneboog, L. (2017). On the foundations of corporate social responsibility. The Journal of Finance, 115(2), 304-329.

Liang, H., \& Renneboog, L. (2020). The global sustainability footprint of sovereign wealth funds. Oxford Review of Economic Policy, $36(2), 380-426$.

Lins, K. V., Servaes, H., \& Tamayo, A. (2017). Social capital, trust, and firm performance: The value of corporate social responsibility during the financial crisis. The Journal of Finance, 72(4), $1785-1824$.

Logsdon, J. M., \& Buren, H. J. V. (2009). Beyond the proxy vote: Dialogues between shareholder activists and corporations. Journal of Business Ethics, 87(1), 353-365.

Margolis, J. D., H. A. Elfenbein, and J. P. Walsh (2011). Does it Pay to Be Good... And Does it Matter? A Meta-Analysis of the Relationship between Corporate Social and Financial Performance. Working paper.

Nelson, J. M. (2006). The CalPERS effect revisited again. Journal of Corporate Finance, 12(2), 187-213.
Nilsson, J. (2008). Investment with a conscience: Examining the impact of pro-social attitudes and perceived financial performance on socially responsible investment behavior. Journal of Business Ethics, 83(2), 307-325.

Peattie, K., \& Samuel, A. (2018). Fairtrade towns as unconventional networks of ethical activism. Journal of Business Ethics, 153(1), 265-282.

Principles for Responsible Investing (2019). Annual Report 2019.

Rehbein, K., Logsdon, J. M., \& Van Buren, H. J. (2013). Corporate responses to shareholder activists: Considering the dialogue alternative. Journal of Business Ethics, 112(1), 137-154.

Renneboog, L., Ter Horst, J., \& Zhang, C. (2008a). Socially responsible investments: Institutional aspects, performance, and investor behavior. Journal of Banking \& Finance, 32(9), 1723-1742.

Renneboog, L., Ter Horst, J., \& Zhang, C. (2008b). The price of ethics and stakeholder governance: The performance of socially responsible mutual funds. Journal of Corporate Finance, 14(3), 302-322.

Renneboog, L., Ter Horst, J., \& Zhang, C. (2011). Is ethical money financially smart? Nonfinancial attributes and money flows of socially responsible investment funds. Journal of Fianancial Intermediation, 20(4), 562-588.

Salzmann, A. J. (2013). The integration of sustainability into the theory and practice of finance: An overview of the state of the art and outline of future developments. Journal of Business Economics, 83(6), 555-576.

Scholtens, B. (2006). Finance as a driver of corporate social responsibility. Journal of Business Ethics, 68(1), 19-33.

Servaes, H., \& Tamayo, A. (2013). The impact of corporate social responsibility on firm value: The role of customer awareness. Management Science, 59(5), 1045-1061.

Sievänen, R., Rita, H., \& Scholtens, B. (2013). The drivers of responsible investment: The case of European pension funds. Journal of Business Ethics, 117(1), 137-151.

Smith, M. P. (1996). Shareholder activism by institutional investors: Evidence from CalPERS. The Journal of Finance, 51(1), 227-252.

Stuart, E. A. (2010). Matching methods for causal inference: A review and a look forward. Statistical Science, 25(1), 1-21.

US SIF (2019). Annual Report: US SIF and US SIF Foundation. US SIF.

Watkins, M. (2010). How BP Could Have Avoided Disaster. Harvard Business Review,88(6).

Publisher's Note Springer Nature remains neutral with regard to jurisdictional claims in published maps and institutional affiliations. 